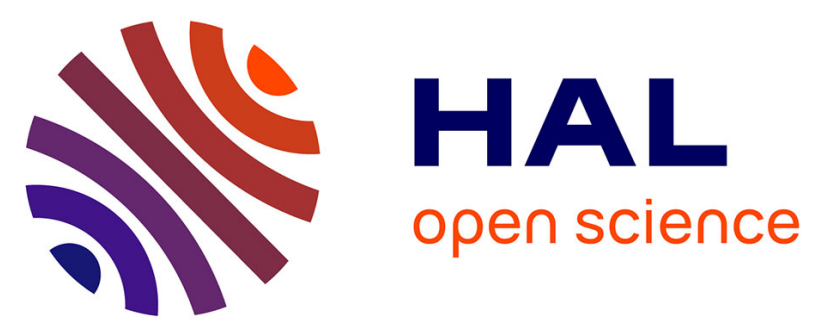

\title{
An original simplified method based on the use of an adjustable localization operator for low-cycle fatigue life predictions in the case of confined plasticity
}

Bruno Levieil, Cédric Doudard, David Thevenet, Florent Bridier, Anthony Ezanno, Sylvain Calloch

\section{To cite this version:}

Bruno Levieil, Cédric Doudard, David Thevenet, Florent Bridier, Anthony Ezanno, et al.. An original simplified method based on the use of an adjustable localization operator for low-cycle fatigue life predictions in the case of confined plasticity. Theoretical and Applied Fracture Mechanics, 2019, 104, pp.102383. 10.1016/j.tafmec.2019.102383 . hal-02354234

\section{HAL Id: hal-02354234 \\ https://hal-ensta-bretagne.archives-ouvertes.fr/hal-02354234}

Submitted on 27 Sep 2021

HAL is a multi-disciplinary open access archive for the deposit and dissemination of scientific research documents, whether they are published or not. The documents may come from teaching and research institutions in France or abroad, or from public or private research centers.
L'archive ouverte pluridisciplinaire HAL, est destinée au dépôt et à la diffusion de documents scientifiques de niveau recherche, publiés ou non, émanant des établissements d'enseignement et de recherche français ou étrangers, des laboratoires publics ou privés. 


\title{
An original simplified method based on the use of an adjustable localization operator for low-cycle fatigue life predictions in the case of confined plasticity
}

\author{
Bruno Levieil $^{\mathrm{a}, *}$, Cédric Doudard ${ }^{\mathrm{a}}$, David Thevenet ${ }^{\mathrm{a}}$, Florent Bridier ${ }^{\mathrm{b}}$, Anthony Ezanno ${ }^{\mathrm{c}}$, \\ Sylvain Calloch ${ }^{\mathrm{a}}$ \\ ${ }^{\text {a }}$ ENSTA Bretagne, UMR CNRS 6027, IRDL, F-29200 Brest, France \\ ${ }^{\mathrm{b}}$ Naval Group, 40-42 rue du docteur Finlay, F-75732 Paris, France \\ ${ }^{\mathrm{c}}$ DGA Techniques navales, Avenue de la Tour Royale, BP 40915, 83050 Toulon Cedex, France
}

\begin{abstract}
This study aims to propose a methodology to rapidly obtain low-cycle fatigue life predictions. The main idea is to use a recently developed simplified method to estimate the stabilized stress-strain curve in confined plasticity in order to apply a fatigue criterion. This original simplified method is based on the use of an adjustable scale transition rule which has been demonstrated to be more robust to multiaxial loadings than classic plasticity correction rules. Different procedures are used to calibrate the localization operator and are compared to each other. The whole method is validated on a double notched specimen subjected either to compressive or tensile repeated loading. Kinematics and isotropic hardenings with threshold are used to model the partial mean stress relaxation that is observed experimentally. A modification of the Morrow fatigue criterion is proposed to enhance the prediction of the influence of the load ratio, represented by the local stabilized mean stress. The full design chain validation on notched specimens has shown a constant conservatism on the fatigue life predictions whatever the nominal load ratio and level. The results obtained with the simplified method are very similar to those obtained with finite elements.
\end{abstract}

\section{Introduction}

Fatigue life prediction of complex structures in low-cycle fatigue is still an industrial challenge. Indeed, the application of fatigue life criteria such as those proposed by Morrow [1] or Smith-Watson-Topper [2] requires the determination of the stabilized cyclic strain-stress curve. These values have to be determined at the critical point, around which confined plasticity frequently appears. This can be achieved with finite element analysis but the number of elements necessary to obtain a converged solution at the critical point may impede this solution for large structures. The number of cycles necessary to obtain a stabilized solution is also often a problem because of the plasticity that generally occurs during low-cycle fatigue and induces progressive slow meanstress relaxation.

In order to avoid long and costly finite element computations, rapid simplified methods have been developed. Their aim is to estimate the strain-stress histories during cyclic loadings only at the critical point. As early as 1961, Neuber [3] proposed a rule for shear strained prismatic bodies with notches. Another approach has been then proposed by Molski-Glinka [4] called the equivalent strain energy density (ESED) method. Later on, Moftakhar [5] suggested that Neuber's rule can be considered as an upper bound estimation whereas ESED as lower bound estimation of the actual elasto-plastic notch tip behavior. For the last 40 years, several authors have worked on the energetic interpretation of Neuber's rule [6-10] and on its extension to different loading conditions such as multiaxial cases [5,11-15]. Nevertheless, it is established that the predictive capability of Neuber's rule or of ESED method remains dependent on the material constitutive behavior and the mode of loading [16-20].

More recently, Herbland [21] has proposed another method to solve the problem in the general multiaxial case. This method is based on the use of an adjustable scale transition rule. It implies the calibration of a localization operator, using the results of a finite element (FE) simulation of the first load. Darlet [15] has subsequently proposed a similar approach by using another identification method of the localization operator. The aim of this paper is to propose a full design chain

\footnotetext{
* Corresponding author.

E-mail address: bruno.levieil@ensta-bretagne.org (B. Levieil).
} 


\section{Nomenclature}

b Manson-Coffin criterion exponent

$\boldsymbol{b}_{\boldsymbol{i}} \quad$ kinetic parameter of the isotropic hardening

c Basquin criterion exponent

$\boldsymbol{C}_{\boldsymbol{i}} \quad$ linear parameter of the kinematic hardening

dp equivalent plasticity rate

$\mathbf{d} \epsilon_{\boldsymbol{p}} \quad$ plasticity rate

$\boldsymbol{E}^{-} \quad$ Young's modulus

$\boldsymbol{f} \quad$ yield surface

$\boldsymbol{G} \quad$ shear modulus

$\underline{\underline{J}} \quad$ deviatoric projector

$\bar{J}_{2}(\sigma) \quad$ von Mises equivalent stress

$\boldsymbol{K}_{T}^{\nu} \quad$ stress concentration operator considering the material Poisson's coefficient

$\boldsymbol{K}_{T}^{\mathbf{0 . 5}} \quad$ stress concentration operator considering a 0.5 Poisson's coefficient

$\underline{L} \quad$ localization operator

$\underline{\underline{\underline{L}}}^{D} \quad$ Darlet localization operator

$\underline{\underline{L}}^{E} \quad$ Eshelby operator

$\underline{\underline{L}}^{H} \quad$ Herbland localization operator

$\boldsymbol{N}_{\boldsymbol{i}} \quad$ number of cycles to initiation

$\boldsymbol{p} \quad$ accumulated plastic strain

$\boldsymbol{Q}_{\boldsymbol{i}} \quad$ asymptotic parameter of the isotropic hardening

$\boldsymbol{R}_{\text {limi }} \quad$ threshold parameter of the isotropic hardening

$\boldsymbol{R}_{\boldsymbol{i}} \quad$ isotropic hardening

$\boldsymbol{R}_{\varepsilon} \quad$ strain ratio

$\boldsymbol{R}_{\sigma} \quad$ stress ratio

$\boldsymbol{R}_{\sigma}^{\text {loc }} \quad$ local stress ratio

$\boldsymbol{R}_{\sigma}^{\text {nom }}$ nominal stress ratio

$\boldsymbol{X}_{\boldsymbol{i}} \quad$ kinematic hardening

$\bar{X}_{\text {limi }} \quad$ threshold parameter of the kinematic hardening

$\boldsymbol{z} \quad$ surface inclusion parameter

$\boldsymbol{Z} \quad$ surface inclusion constant $\beta \quad$ Eshelby parameter

$\Delta \epsilon \quad$ cyclic strain range

$\Delta \epsilon_{e q} \quad$ equivalent strain range

$\Delta \sigma \quad$ cyclic stress range

$\gamma_{i} \quad$ kinetic parameter of the kinematic hardening

$\underline{\epsilon} \quad$ strain tensor

$\epsilon_{\boldsymbol{a}} \quad$ strain amplitude

$\underline{\epsilon}_{e} \quad$ elastic strain tensor

$\bar{\epsilon}^{I} \quad$ strain tensor in an inclusion

$\varepsilon_{f} \quad$ Basquin criterion parameter

$\epsilon_{p} \quad$ plastic strain tensor

$\underline{\sigma}^{I} \quad$ stress tensor in an inclusion

$\underline{\sigma}^{l o c} \quad$ local stress tensor

$\sigma_{\max }^{\text {loc }}$ maximum local stress tensor

$\bar{\sigma}_{\min }^{\text {loc }}$ minimum local stress tensor

$\sigma_{m} \quad$ mean stress

$\sigma_{m}^{e q} \quad$ equivalent mean stress

$\sigma_{\max } \quad$ maximum stress

$\sigma_{\text {max }}^{\text {eq }} \quad$ equivalent maximum stress

$\sigma_{\max }^{\text {nom }}$ maximum nominal stress

$\sigma_{\text {min }}^{\text {nom }} \quad$ minimum nominal stress

$\sigma_{r} \quad$ elastic stress estimation

$\sigma_{y} \quad$ elastic stress integrating this new approach and to compare the predictions given by this chain with experimental results.

Experimental validation is accomplished on plate specimens with two notches, used to induce confined plasticity. In this study, Darlet's and Herbland's identification methods will thus be used and compared with one another as well as with FE predictions and experimental results. The discussion will cover key elements of strain-stress histories with focus on the chosen fatigue criterion, in particular in the case of compressive mean stress. This specific load case can occur under compressive loadings or when the structure presents compressive residual stresses [22]. It has been less studied than tensile loading cases that are more frequent in the literature [23-26].

The present paper is divided into five main sections. First, the fatigue tests conducted on notched specimens that will be used for the method validation are presented. Then, simplified methods for local stress/strain calculation are introduced with a focus on Darlet's and Herbland's propositions.

In the third part, the material behavior is identified. Its elastoplastic behavior is described using two alternative behavior laws identified using an original sequential identification procedure: a first law with classical non-linear hardenings as proposed by Armstrong \& Frederick [27] and Voce [28]; and an original second law with threshold hardenings [29].

The aim of using these two laws is to underline their mean stress relaxation prediction capability. Then, purely alternated strain controlled tests on axisymmetric specimens are performed to identify the low-cycle fatigue properties. A modification of the Morrow fatigue criterion is proposed to enhance the prediction of the mean stress effect, in the particular case of compressive mean stress. This experimental part is achieved with the introduction of the fatigue testing on notched specimens under tensile or compressive repeated loadings.

In the fourth part, Herbland's and Darlet's parameters are calculated using the material behavior law on a quasi-static finite element analysis. The predictions of the stabilized stress-strain curves obtained with the simplified methods are thus compared to those obtained using a reference non-linear finite element cyclic analysis rather than to compare results to other simplified methods such as Neuber or ESED. Indeed, the results obtained with finite elements analysis are considered the most accurate. The same comparative work is accomplished employing the stabilized parameters used for the fatigue life calculation. The last part of this paper aims at validating the fatigue life prediction for the notched specimens. A multiaxial equivalent formulation of the scalar parameters used in the fatigue life criterion is proposed. Fatigue life prediction can then be obtained. A comparison is made with the experimental data obtained on the notched specimens under tensile repeated loadings or compressive repeated loadings.

\section{Case study}

Fatigue tests were conducted on ferritic high-strength steel specimens under two different load ratios. The geometry of these notched specimens is indicated in Fig. 1. These specimens were machined with an electrical discharge machine. A slight electro-polishing was performed at the notch surface to reduce all residual stresses. Initial stress measurements were achieved using an X-Ray diffraction device. All initial residual stresses were lower than $5 \%$ of the material elastic limit.

A nominal stress-controlled loading was applied at the end of the notched specimens in the $\vec{e}_{\mathbf{1}}$ direction. The nominal maximal principal 

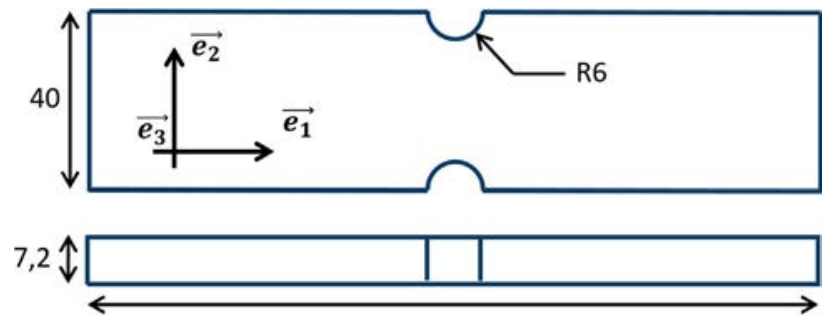

160

Fig. 1. Specimen geometry (units in $\mathrm{mm}$ ).

stress ratio is defined, in a multiaxial proportional case, by

$\boldsymbol{R}_{\sigma}^{\text {nom }}=\sigma_{\text {min }}^{\text {nom }} / \sigma_{\text {max }}^{\text {nom }}$.

The notched specimens were tested in fatigue for repeated nominal stress loads. Compressive $\left(R_{\sigma}^{\text {nom }}=-\infty\right)$ and tensile $\left(R_{\sigma}^{\text {nom }}=0\right)$ nominal loads were applied. Fatigue tests were conducted at $2 \mathrm{~Hz}$. Crack initiation was detected with the alternating current potential drop technique [30] calibrated for a $0.8 \mathrm{~mm}$ crack length. Two distinct Wöhler curves, shown in Fig. 2, were obtained indicating that, as expected, the nominal stress ratio has an important effect as compressive tests showed longer lifespan. It is worth noting that, although the nominal stress ratio is controlled, the local stress ratio can only be evaluated numerically and evolves during the test until strain and stresses are stabilized.

\section{Simplified methods and fast prediction of stabilized stress- strain curves in a located plastic zone}

When confined plasticity appears around notches or any other geometric singularity, a specific methodology has to be employed to predict the stabilized stress-strain curve, necessary for the fatigue criterion application. Cyclic finite element analysis is a common solution, but the computation time necessary to obtain an accurate prediction of the stabilized stress-strain curve can be costly due to the local plastic behavior that induces slow cyclic stress relaxation. This is an additional motivation to the development of simplified methods to estimate the stabilized stress-strain curve only at the critical point.

Since Neuber's rule [3], many authors have proposed different simplified approaches $[4,5,31]$. In recent years, Herbland has proposed a multiaxial approach that has shown better correlation under cyclic multiaxial loadings with numerical finite element analysis predictions than Neuber's method $[32,33]$. Herbland's method is based on the use of a relationship between the stress tensor at the critical point, $\underline{\sigma}^{\text {loc }}$, and the stress tensor at the same point if an elastic behavior is assumed, inspired by localization laws of multi-scale approaches [34]. Fig. 3 illustrates the analogy between the confined plasticity problem and the localization problem written for an elasto-plastic inclusion in an elastic matrix $[35,36]$. For this problem the stress tensor in the inclusion, $\underline{\sigma}^{I}$, can be related to the stress tensor applied in the matrix, $\underline{\Sigma}$, by

$\underline{\dot{\sigma}}^{I}=\underline{\dot{\Sigma}}-\underline{\underline{L}}^{E}: \underline{\dot{\epsilon}}_{p}^{I}$

where $\epsilon_{p}^{I}$ is the plastic strain tensor in the inclusion. The dot operator over a letter refers to its time derivative. $\underline{\underline{L}}^{E}$ is Eshelby's fourth-order localization operator, which depends on the shear modulus, $\boldsymbol{G}$, and the Poisson's ratio of the material, $\nu$,

$\underline{\underline{L}}^{E}=2 G(1-\beta) \underline{\underline{J}}$

with

$\beta=\frac{2(4-5 \nu)}{15(1-v)}$,

given by the Eshelby analysis [34], and $\underline{\underline{J}}$ the deviatoric projector expressed as

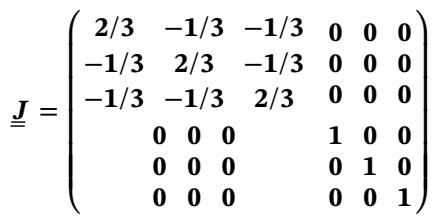

in Voigt notation.

For the confined plasticity problem, Eq. (2) can be replaced by

$\underline{\dot{\sigma}}^{l o c}=\underline{K}_{T}^{\nu} \underline{\dot{\sigma}}^{n o m}-\underline{\underline{L}}: \dot{\underline{\epsilon}}_{p}^{l o c}$

where $\boldsymbol{K}_{T}^{\nu}$ is the fourth-order tensor of the stress concentration factors calibrated on any elastic increment of the finite element simulation, $\epsilon_{\boldsymbol{p}}^{\text {loc }}$ is the plastic strain tensor at the critical point. As this problem is different from Eshelby's problem, the localization operator $\underline{\underline{L}}$ differs. It depends on the material, the geometry and the loading conditions.

However, some simplifications can be performed to reduce the number of terms to be identified using the free edge condition and the symmetries at the critical point [21]. Assuming $\left(\overrightarrow{\boldsymbol{e}}_{2}\right)$ is the normal direction to the free surface, tensors can be simplified to

$\underline{\sigma}^{l o c}=\left(\begin{array}{c}\sigma_{11} \\ 0 \\ \sigma_{33} \\ 0 \\ \sigma_{13} \\ 0\end{array}\right), \epsilon_{p}^{l o c}=\left(\begin{array}{c}\epsilon_{p, 11}^{l o c} \\ 0 \\ \epsilon_{p, 33}^{l o c} \\ 0 \\ \epsilon_{p, 13}^{l o c} \\ 0\end{array}\right), \underline{L}=\left(\begin{array}{cccccc}L_{1111} & 0 & L_{1133} & 0 & 0 & 0 \\ 0 & 0 & 0 & 0 & 0 & 0 \\ L_{1133} & 0 & L_{3333} & 0 & 0 & 0 \\ 0 & 0 & 0 & 0 & 0 & 0 \\ 0 & 0 & 0 & 0 & L_{1313} & 0 \\ 0 & 0 & 0 & 0 & 0 & 0\end{array}\right)$.

Herbland proposed to identity the localization operator (denoted $\underline{\underline{L}}^{\boldsymbol{H}}$ in this case) on the numerical elasto-plastic simulation of the first quarter cycle. Once the localization and the stress concentration operators are identified the cyclic stress-strain curves are simulated analytically for a few tens of cycles until the critical point behavior is stabilized. The analytical calculation is immediate which means that the numerical cost is only the cost of simulating the first quarter cycle. In order to obtain the Wöhler curve, only the highest load has to be simulated and the different values of the localization operators are obtained thanks to the different increments of the calculation.

More recently, Darlet et al. [15] have proposed another methodology to identify this localization operator thanks to the analogy with a hemispheric inclusion at the surface of a matrix (Fig. 3). The localization operator can then be written as

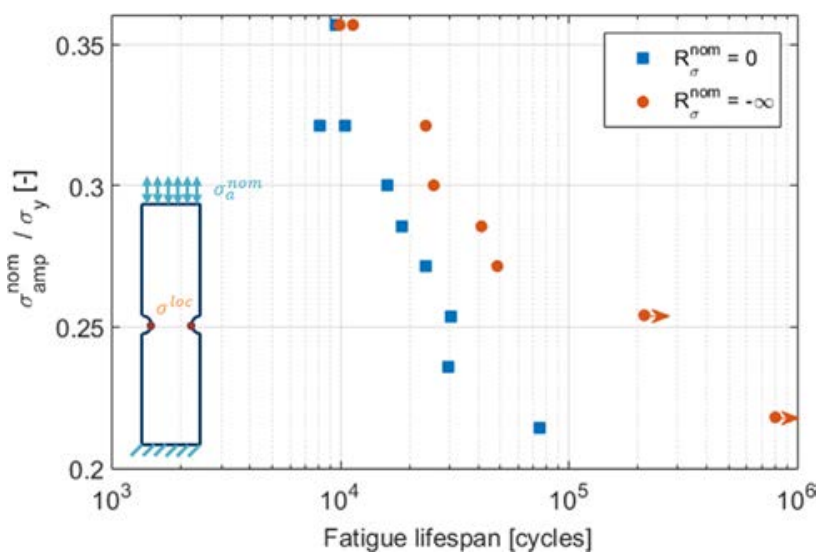

Fig. 2. Fatigue curves of the notched specimen for two nominal load ratios. 


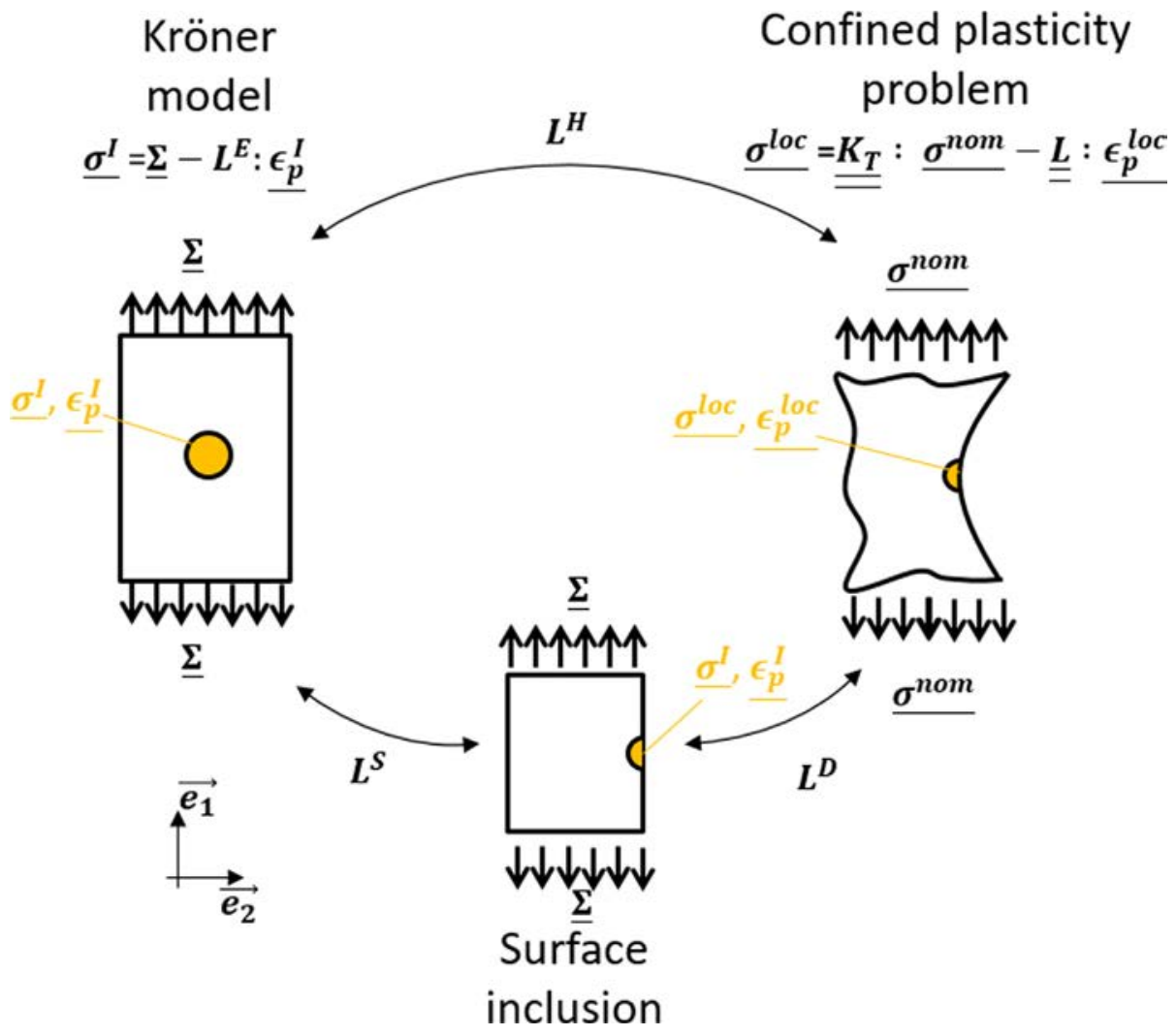

Fig. 3. Analogy between Kröner's approach and the confined plasticity problem.

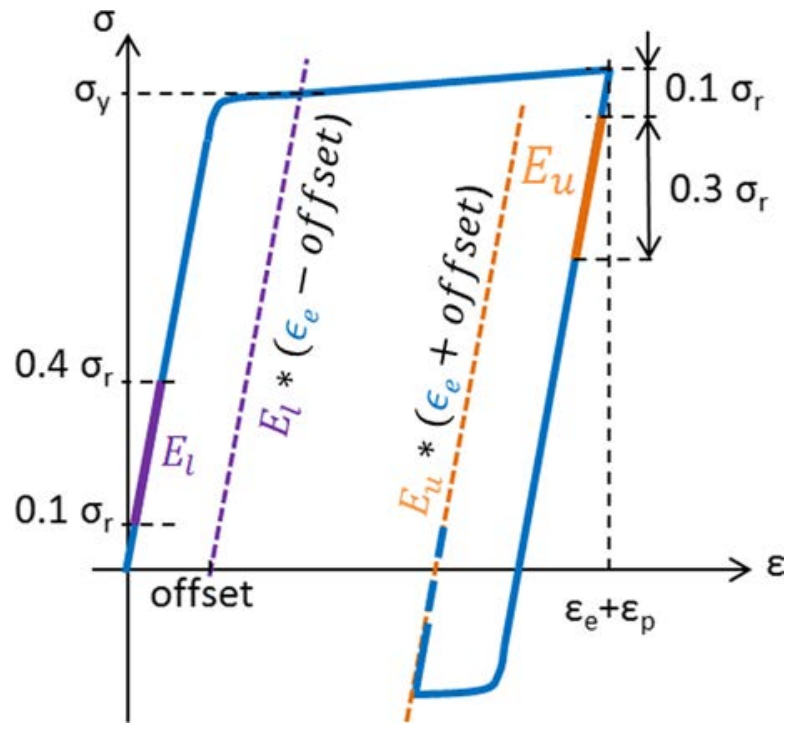

Fig. 4. Load-unload test control procedure.
(8)

Sauzay numerically estimated $Z=\mathbf{1 . 7 9}$ and $\boldsymbol{z}=\mathbf{0 . 7 9} / \boldsymbol{Z}$ in the case of a flat surface [37]. For the confined plasticity problem, Darlet proposed to consider $\boldsymbol{Z}=\mathbf{1 . 7 9}$ as for the reference problem but a value of $\boldsymbol{z}$ which depends of the material, the geometry and the loading conditions. To determine the expression of this parameter, it is worth noting that the localization equation implies a direction move in the stress space for $\underline{\dot{\sigma}}^{l o c}$, when plasticity appears except in specific cases, i.e., that $\underline{\dot{\sigma}}^{\text {loc }}$ does not remain proportional to $\boldsymbol{K}_{T}^{\nu}$ : $\underline{\dot{\sigma}}^{\text {nom }}$ [9]. Darlet showed that when $\epsilon_{p}^{\text {loc }} \gg \epsilon_{e}^{\text {loc }}$, it can be assumed that

$\underline{\sigma}^{l o c} \propto \underline{K}_{T}^{0.5}: \underline{\sigma}^{\text {nom }}$

with $\boldsymbol{K}_{T}^{0.5}$ the stress concentration tensor using a 0.5 Poisson's coefficient.

For the same configuration (i.e., $\epsilon_{p}^{l o c} \gg \epsilon_{e}^{l o c}$ and then $\dot{\epsilon}_{p}^{l o c} \gg \dot{\epsilon}_{e}^{l o c}$ ), Eq. (6) can be simplified as follows

$\underline{\underline{L}} \dot{\epsilon}_{p}^{l o c}=K_{T}^{\nu}: \underline{\dot{\sigma}}^{\text {nom }}$

(i.e., $\underline{\dot{\sigma}}^{\text {loc }}$ is negligible with respect to $\underline{\underline{L}} \dot{\epsilon}_{\boldsymbol{p}}^{\text {loc }}$ ).

Using the normality rule in the previous equation (i.e., the plastic flow is normal to the von Mises yield surface), it can be shown that

$\underline{\underline{L}}: \underline{\underline{J}}: \underline{\sigma}^{l o c} \propto \underline{\underline{K}}^{\nu}: \underline{\dot{\sigma}}^{\text {nom }}$

Using Eq. (9), Eq. (11) can be expressed as

$\underline{\underline{L}}: \underline{\underline{J}}: \underline{\underline{K}}_{T}^{0.5}: \underline{\sigma}^{n o m} \propto \underline{\underline{K}}_{T}^{\nu}: \underline{\dot{\sigma}}^{n o m}$

Considering that the nominal loading direction is $\vec{e}_{\mathbf{1}}$ and the normal direction to the free surface is $\overrightarrow{e_{2}}$, Eq. (12) implies

$\left(\begin{array}{c}\left(1-\frac{z}{2}\right) K_{T, 1111}^{0.5}+\left(z-\frac{1}{2}\right) K_{T, 3311}^{0.5} \\ 0 \\ \left(z-\frac{1}{2}\right) K_{T, 1111}^{0.5}+\left(1-\frac{z}{2}\right) K_{T, 3311}^{0.5}\end{array}\right) \propto\left(\begin{array}{c}K_{T, 1111}^{\nu} \\ 0 \\ K_{T, 3311}^{\nu}\end{array}\right)$

To satisfy this equation, the value of $\boldsymbol{z}$ can be finally be evaluated as

$z=\frac{\frac{K_{T, 3311}^{\nu} K_{T, 3311}^{0.5}}{2}-\frac{K_{T, 1111}^{\nu} K_{T, 1111}^{0.5}}{2}+K_{T, 1111}^{\nu} K_{T, 3311}^{0.5}-K_{T, 3311}^{\nu} K_{T, 1111}^{0.5}}{K_{T, 3311}^{\nu} K_{T, 3311}^{0.5}-K_{T, 1111}^{\nu} K_{T, 1111}^{0.5}+\frac{K_{T 1111}^{\nu} K_{T 3311}^{0.5}}{2}-\frac{K_{T, 3311}^{\nu} K_{T, 1111}^{0.5}}{2}}$. 


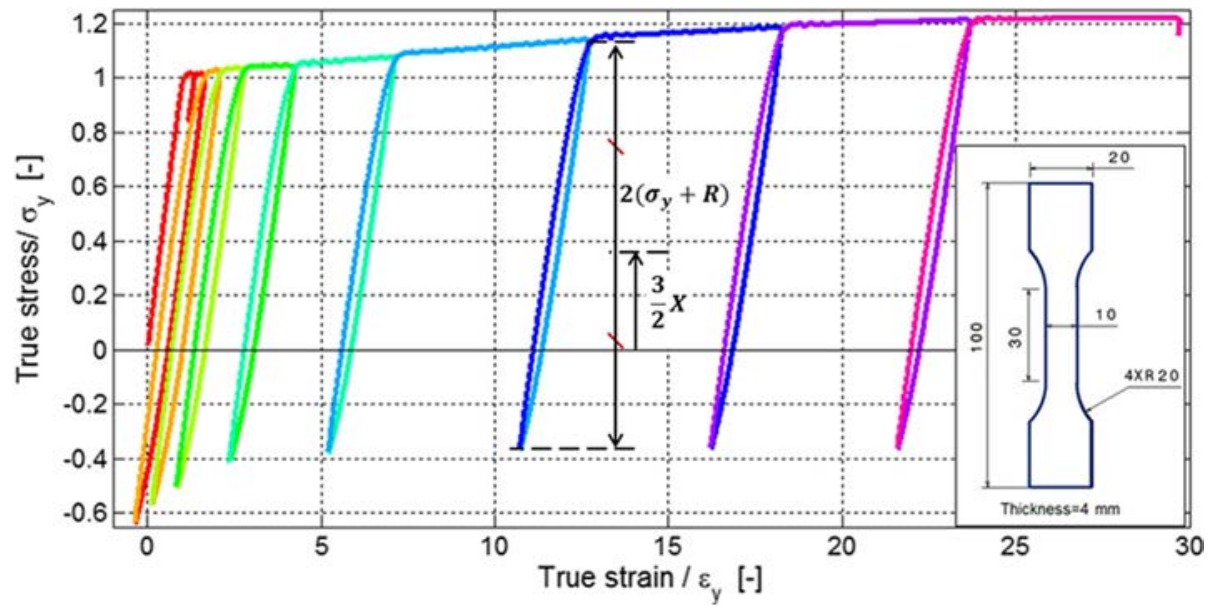

Fig. 5. Load-unload test results.

Table 1

Material parameters for behavior Law 1 (without thresholds).

\begin{tabular}{|c|c|c|c|c|c|c|c|c|c|}
\hline Parameter & $\mathrm{C}_{1} / \sigma_{\mathrm{y}}$ & $\gamma_{1}$ & $\mathrm{C}_{2} / \sigma_{\mathrm{y}}$ & $\mathrm{C}_{3} / \sigma_{\mathrm{y}}$ & $\gamma_{3}$ & $\mathrm{X}_{\lim , 3} / \sigma_{\mathrm{y}}$ & $b_{1}$ & $\mathrm{Q}_{1} / \sigma_{\mathrm{y}}$ & $\mathrm{R}_{\lim , \mathbf{1}} / \sigma_{\mathrm{y}}$ \\
\hline Value & 85.7 & 5000 & 3.14 & 500 & 1000 & 0 & 1000 & -0.500 & 0 \\
\hline
\end{tabular}

Table 2

Material parameters for behavior Law 2 (with thresholds).

\begin{tabular}{|c|c|c|c|c|c|c|c|c|c|}
\hline Parameter & $\mathrm{C}_{\mathbf{1}} / \sigma_{\mathrm{y}}$ & $\gamma_{1}$ & $\mathrm{C}_{2} / \sigma_{\mathrm{y}}$ & $\mathrm{C}_{3} / \sigma_{\mathrm{y}}$ & $\gamma_{3}$ & $\mathrm{X}_{\lim , 3} / \sigma_{\mathrm{y}}$ & $b_{1}$ & $\mathrm{Q}_{1} / \sigma_{\mathrm{y}}$ & $\mathrm{R}_{\lim , \mathbf{1}} / \sigma_{\mathrm{y}}$ \\
\hline Value & 85.7 & 5000 & 3.14 & 157 & 1000 & 0.343 & 1000 & -0.157 & 0.343 \\
\hline
\end{tabular}

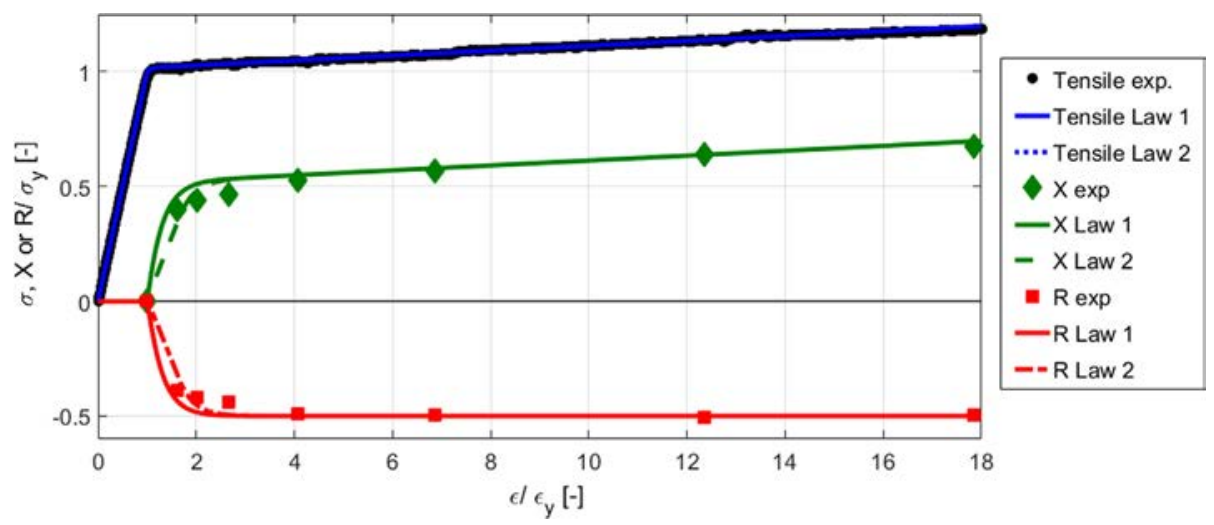

Fig. 6. Stress and hardening evolution with strain for the two behavior laws compared to the experimental data.

As shear stresses and strains can be neglected in this study, Eq. (6) can also be reduces to the following system of equations with three parameters in the localization operator

$\left\{\begin{array}{l}\sigma_{11}^{l o c}=K_{T, 1111}^{\nu} \sigma_{11}^{\text {nom }}-L_{1111} \epsilon_{p, 11}^{l o c}-L_{1133} \epsilon_{I, 33}^{l o c} \\ \sigma_{33}^{l o c}=K_{T, 1133}^{\nu} \sigma_{11}^{\text {nom }}-L_{3333} \epsilon_{p, 33}^{l o c}-L_{1133} \epsilon_{I, 11}^{l o c}\end{array}\right.$

Consequently, to identify the localization operator in Darlet's proposition, two purely elastic FE analysis are needed, one considering the material Poisson's coefficient $v$ and one considering that the Poisson's coefficient is equal to 0.5 to represent the incompressible plastic behavior. The localization operator is the same for every load levels unlike in Herbland's method. In both method, a numerical model is necessary to identify the localization operator and the material elasto-plastic behavior has also to be determined for the analytical cyclic calculation.

\section{Material properties}

\subsection{Material elasto-plastic behavior}

In order to identify the material elasto-plastic behavior, a straincontrolled tensile test is performed with reversed compressive loadings (until the compressive elastic limit was reached) at different chosen plastic strain levels. The objective of this so-called "load-unload" test is to observe the evolution with plastic strain, of the size and the center of the elastic domain, and thus to characterize respectively the material isotropic and kinematic hardenings [38]. The test procedure, illustrated in Fig. 4 is the following:

(1) The specimen is first loaded in tension. The initial Young's modulus is evaluated using a linear regression between two stress values, corresponding approximately to 10 and $40 \%$ of $\sigma_{r}$, where $\sigma_{r}$ is an 


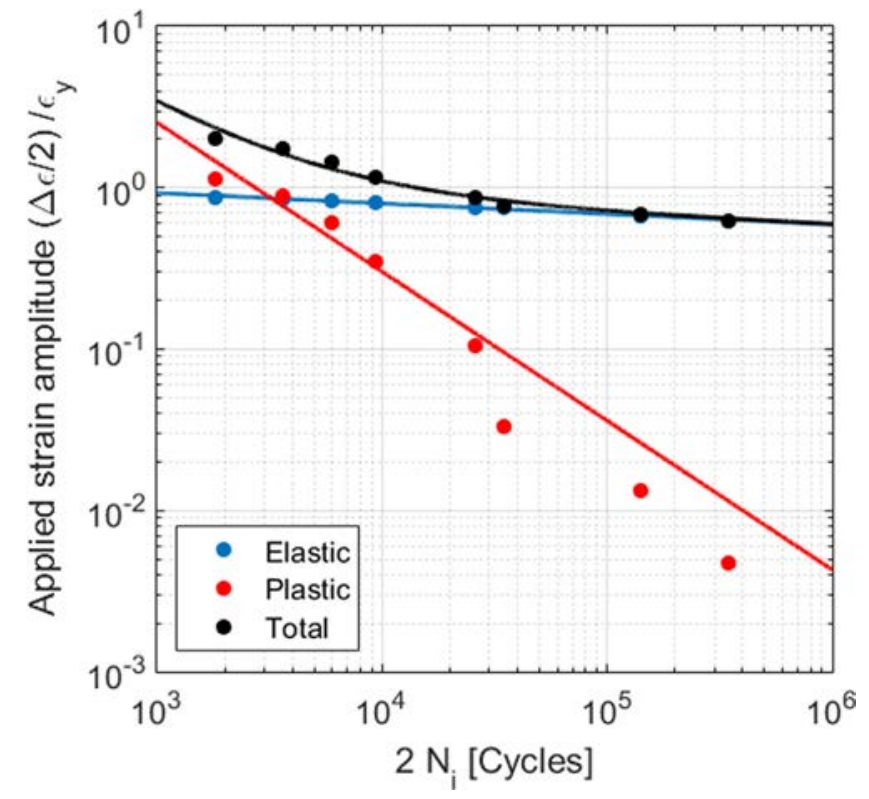

Fig. 7. Identification of MCB parameters for uniaxial cyclic strain-controlled tests $\boldsymbol{R}_{\boldsymbol{\epsilon}}=-\mathbf{1}$.

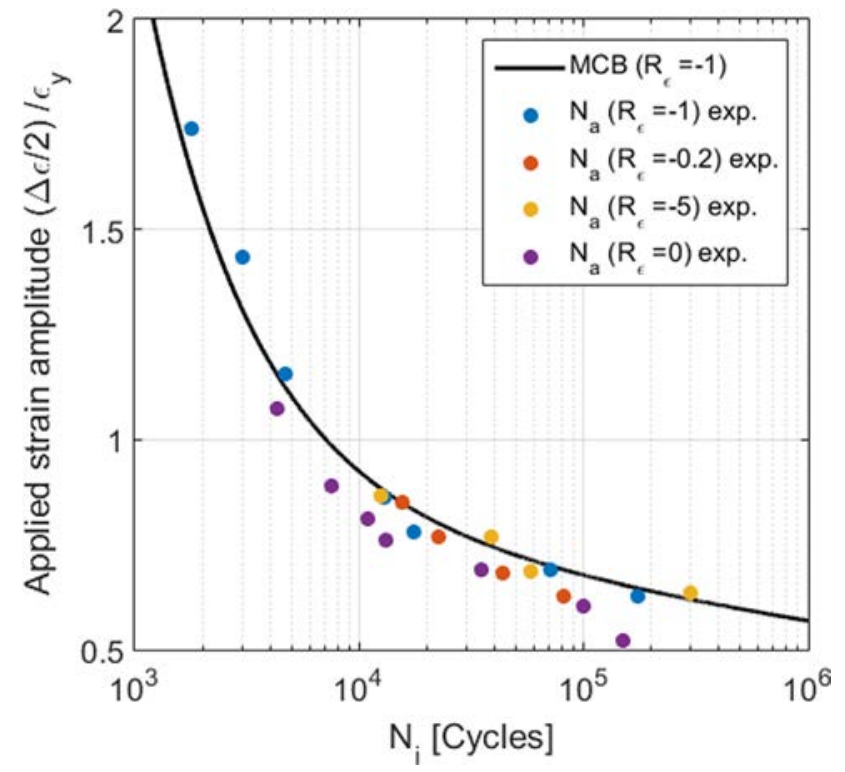

Fig. 9. Fatigue life curves for different load ratios compared to the MansonCoffin-Basquin criterion. a)

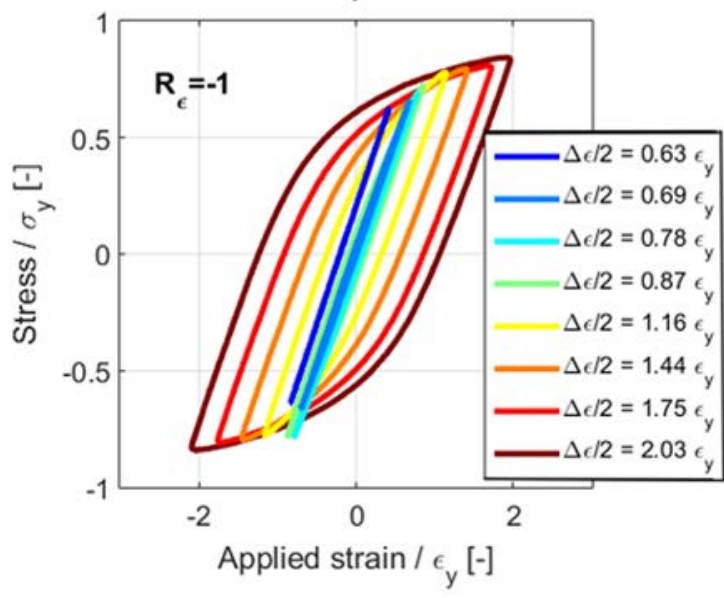

c)

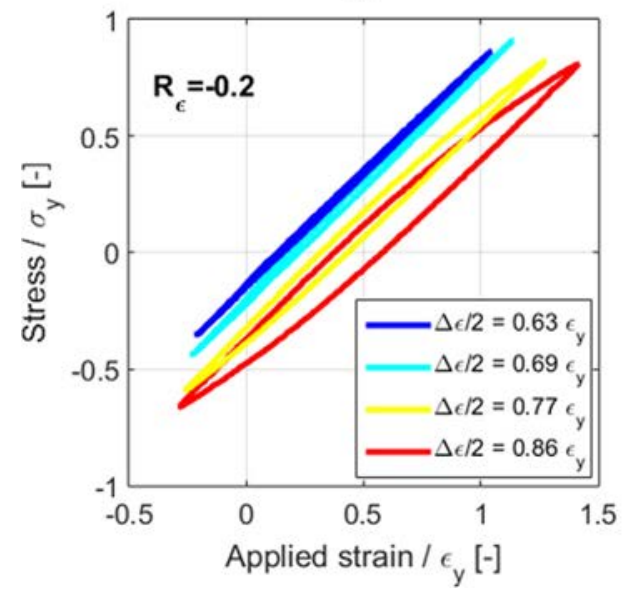

b)

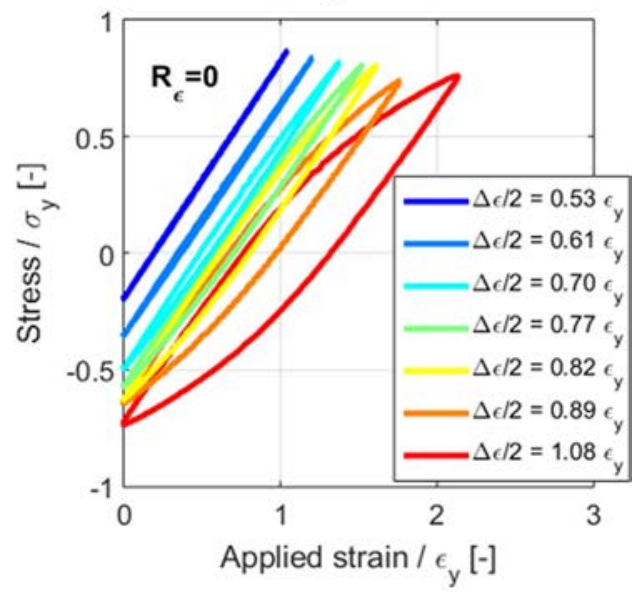

d)

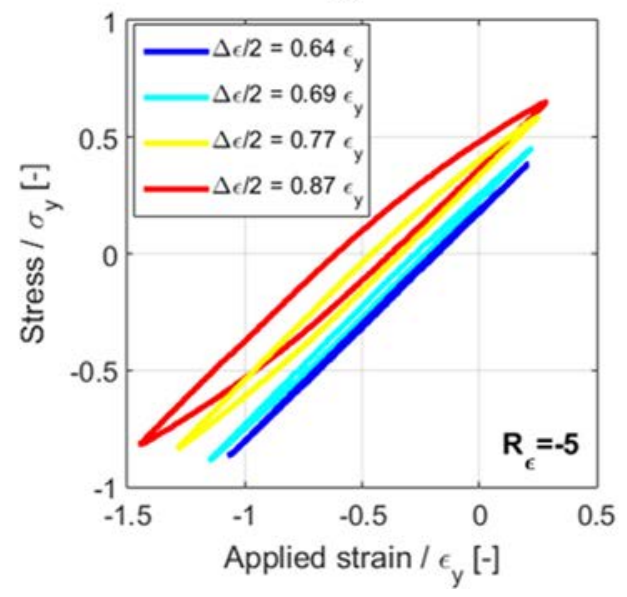

Fig. 8. Stabilized stress-strain curves at $R_{\varepsilon}=-1$ (a), $R_{\varepsilon}=0$ (b), $R_{\varepsilon}=-0.2$ (c) and $R_{\varepsilon}=-5$ (d). 
a)

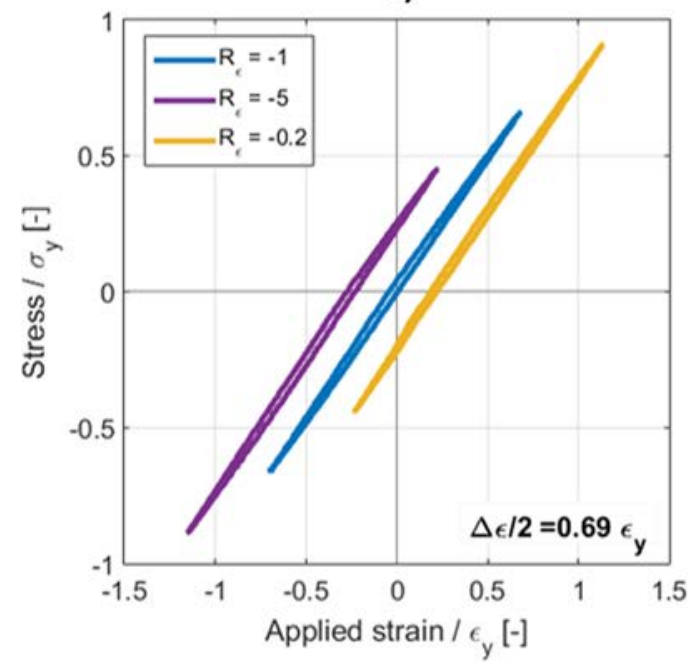

b)

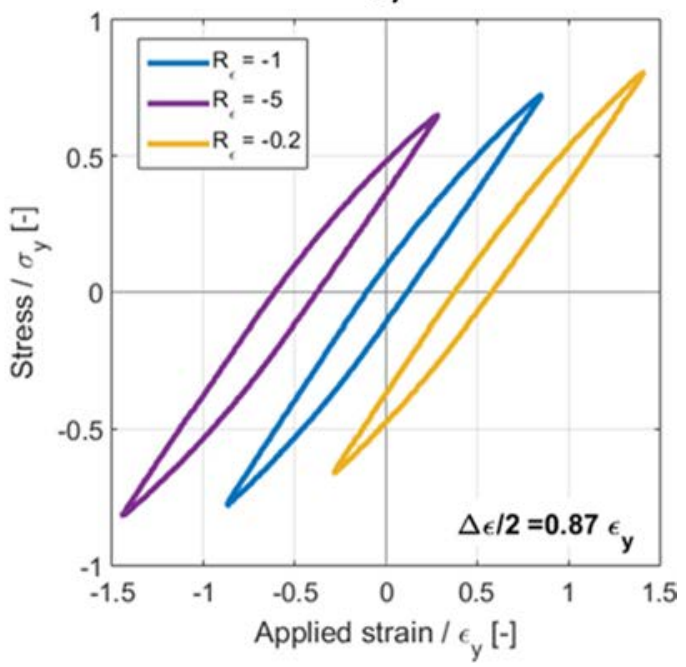

Fig. 10. Experimental stabilized stress/strain curves for three load ratios at two strain amplitudes: $\Delta \varepsilon / 2=0.69 \varepsilon_{\mathrm{y}}(\mathrm{a})$ and $\Delta \varepsilon / 2=0.87 \varepsilon_{\mathrm{y}}$ (b).

a)

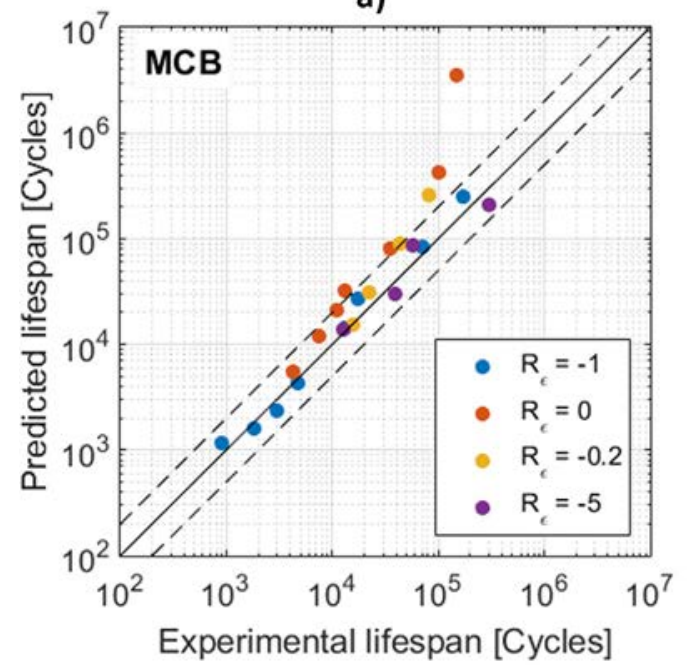

c)

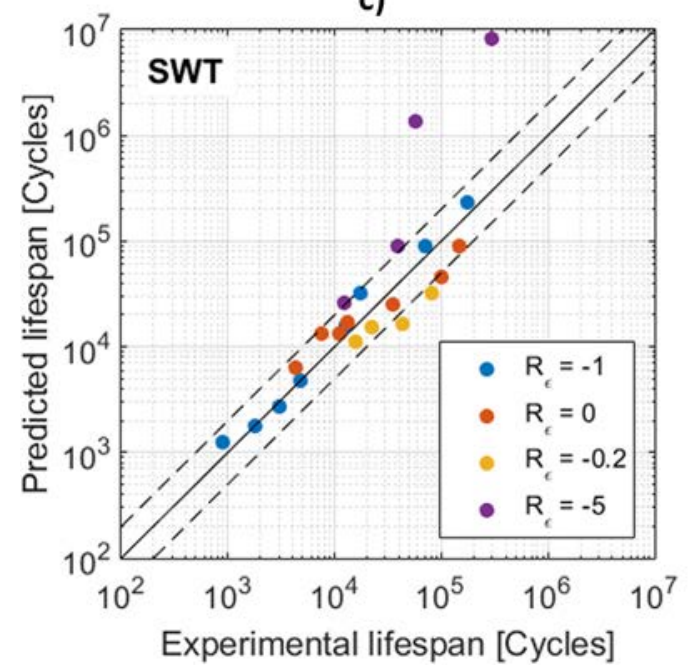

b)

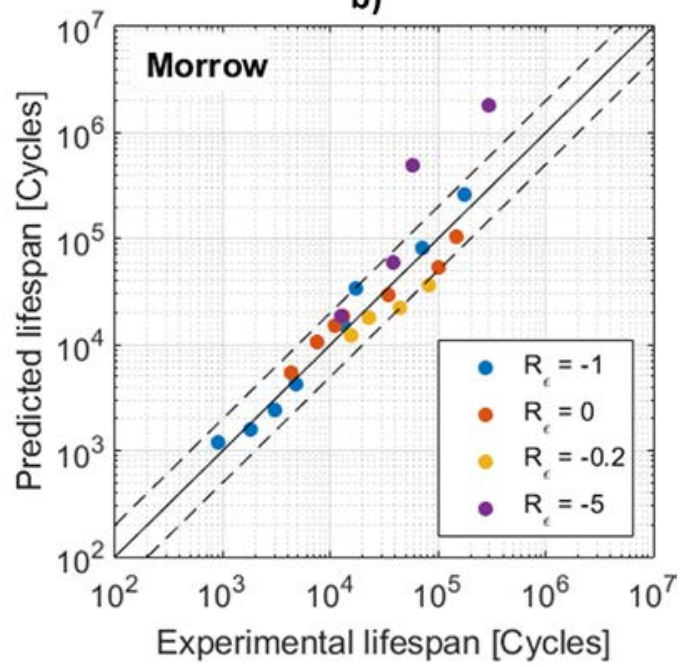

d)

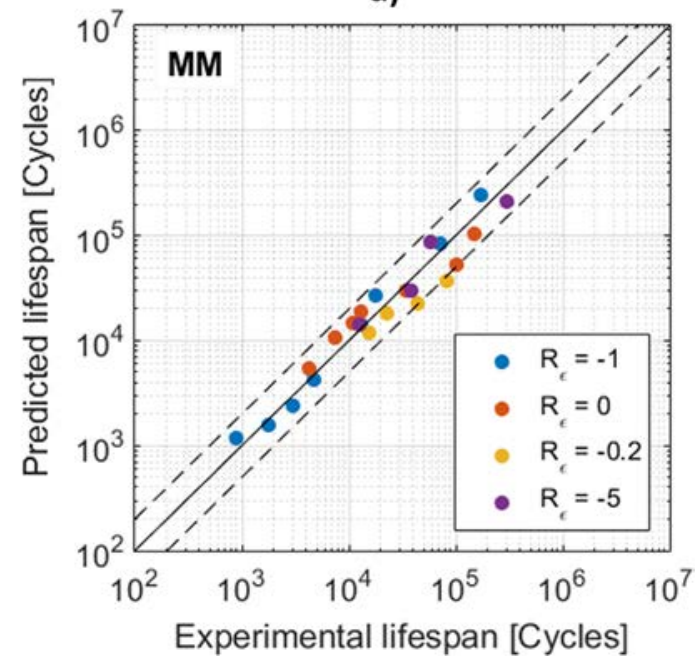

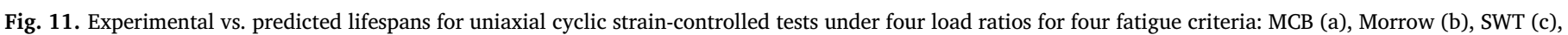
MM (d). Stabilized parameters used for the predictions are measured experimentally. 
a)

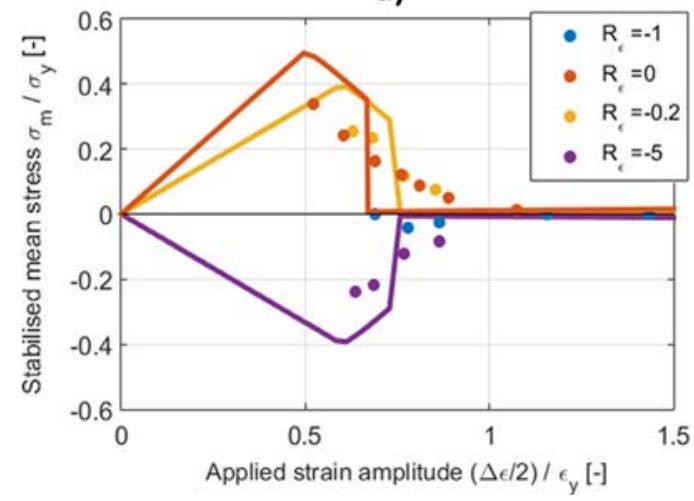

b)

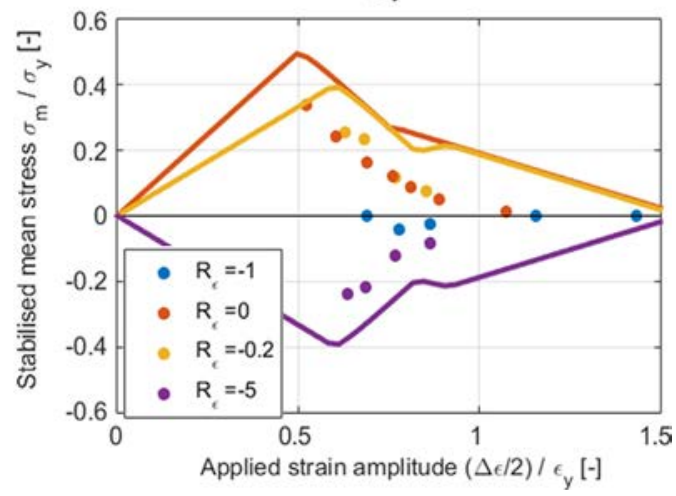

Fig. 12. Comparison of experimental versus predicted mean stress with a classic Chaboche model (a) and with threshold hardenings (b).

a)

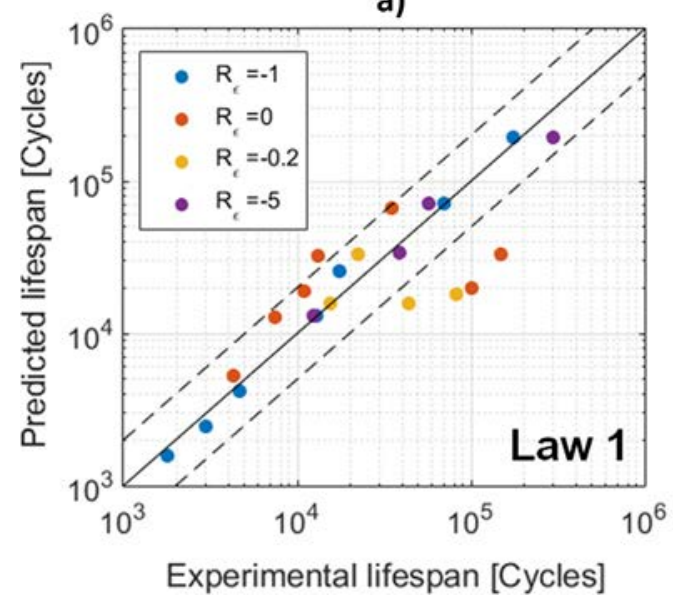

b)

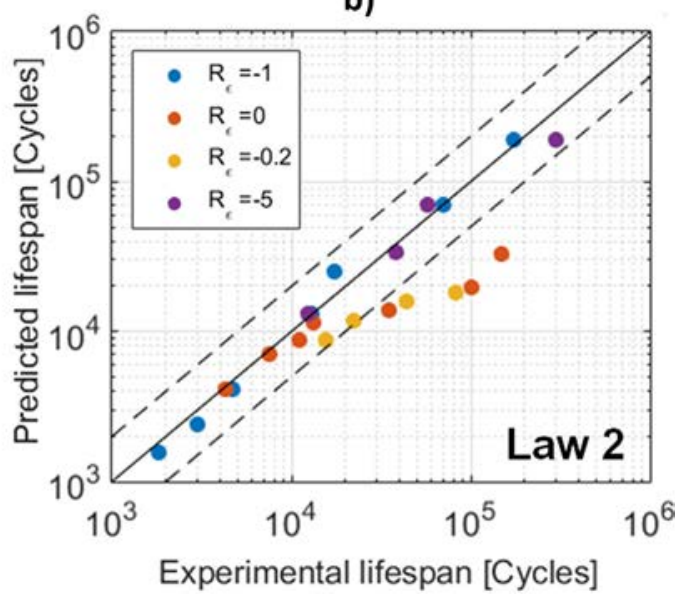

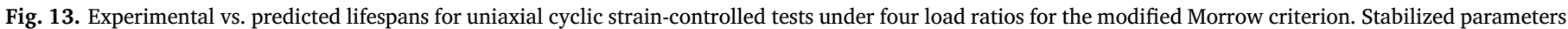
used for the predictions are obtained using Law 1 (11.a). and Law 2 (11.b).

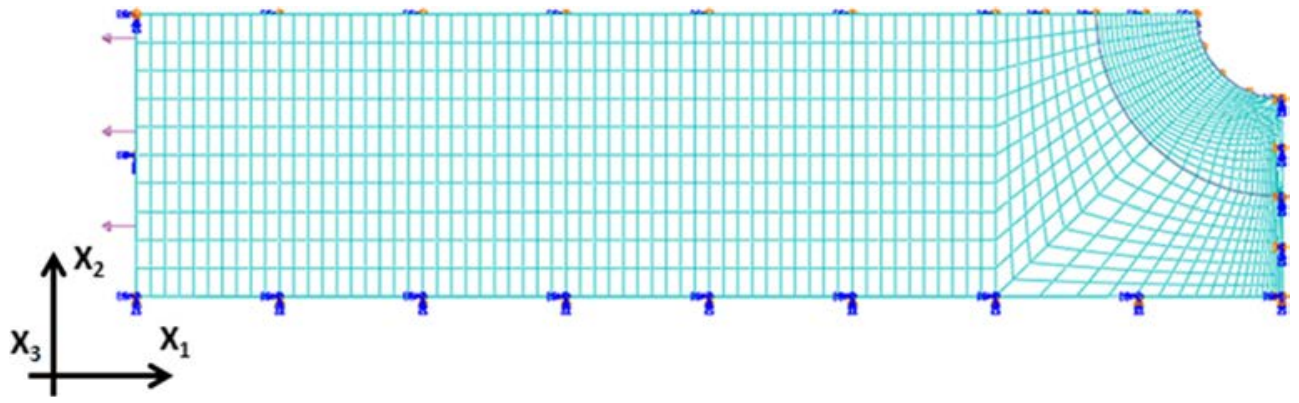

Fig. 14. Part mesh with boundary conditions.

estimation of the initial elastic limit.

(2) When the stress-strain curve crosses the tensile offset line (purple dashed line in Fig. 4), the tensile elastic limit $\sigma_{y}$ is detected. The chosen offset value corresponds to $30 \%$ of the strain at $\sigma_{r}$.

(3) Strain is added until the desired level of plastic strain $\epsilon_{p}$ is reached.

(4) The specimen loading is reversed, unloading the specimen.

(5) The Young's modulus is evaluated again during the unloading on the same range of values as in the previous step. The linear regression was performed between $\sigma_{\max }-\mathbf{0 . 1} \sigma_{r}$ and $\sigma_{\max }-\mathbf{0 . 4} \sigma_{r}$.

(6) When the stress-strain curve crosses the compressive offset line (orange dashed line in Fig. 4), the compressive elastic limit for the chosen plastic strain $\epsilon_{p}$ is detected. The specimen load is reversed again.

(7) Steps 2-6 are repeated for each desired plastic strain level. The
Young's modulus is recalculated for each loading or unloading.

During each unloading, the specimen load varies from the tensile elastic limit to the compressive elastic limit at a given plastic strain.

The load-unload test is plotted in Fig. 5. For confidentiality matter, stresses are normalized by the elastic limit of the material $\sigma_{y}$ and strains by $\boldsymbol{E}_{\boldsymbol{y}}=\sigma_{\boldsymbol{y}} / \boldsymbol{E}$.

This experimental elasto-plastic behavior can be modeled using a mixed model proposed by Chaboche [39]. It combines various isotropic $\left(\boldsymbol{R}_{\boldsymbol{i}}\right)$ and kinematic hardenings $\left(\underline{X}_{\boldsymbol{i}}\right)$. The elastic domain is defined by

$\boldsymbol{f}=\boldsymbol{J}_{2}\left(\underline{\sigma}-\sum \underline{X}_{i}\right)-\left(\sum \boldsymbol{R}_{i}+\sigma_{\boldsymbol{y}}\right)=\mathbf{0}$

where $\boldsymbol{J}_{\mathbf{2}}(\cdot)$ refers to the von Mises equivalent stress. Chaboche proposed a threshold kinematic hardening [29] expressed as 


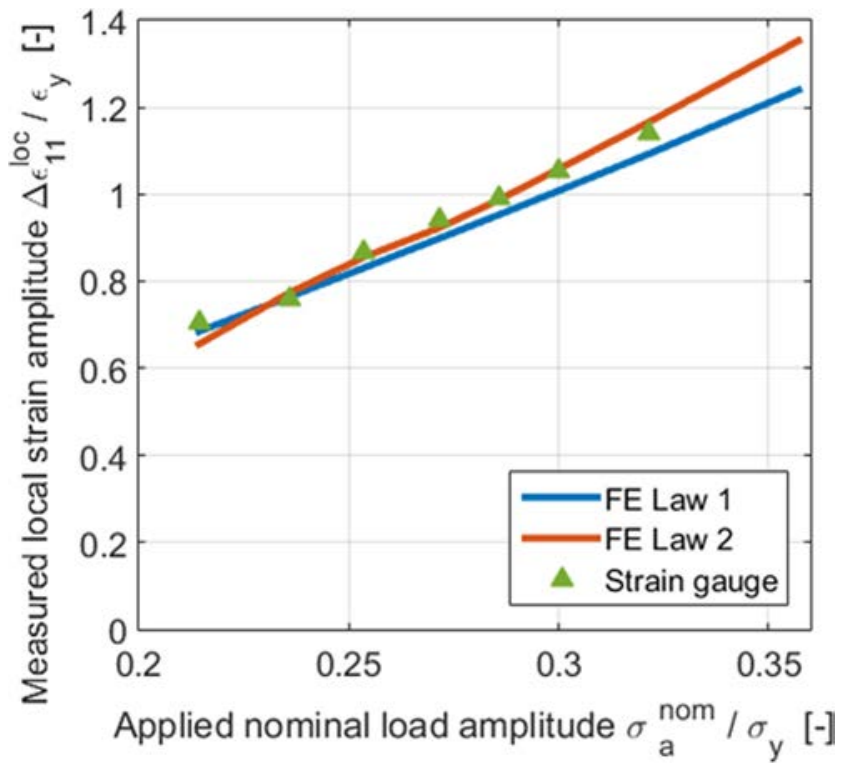

Fig. 15. Comparison between experimental gauge measurements and numerical predictions using the two behavior laws of stabilized strain range in 11 direction.

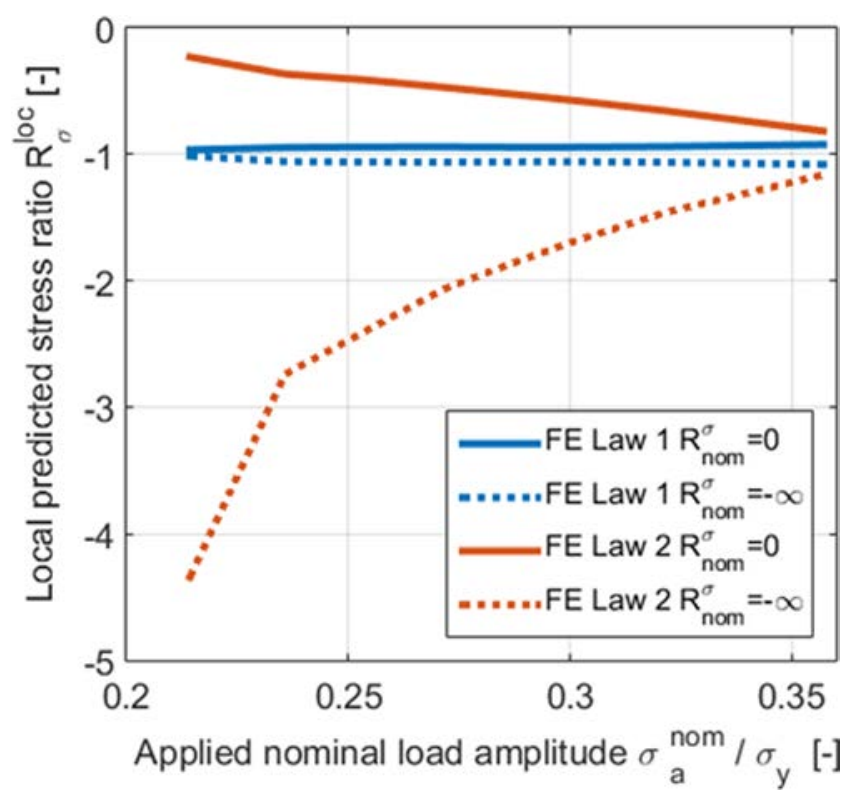

Fig. 16. Numerical predictions of the local stress ratios using the two behavior laws.

$\underline{\dot{X}}_{i}=\frac{2}{3} C_{i} \underline{\dot{\epsilon}}^{p}-\gamma_{i}\left\langle 1-\frac{X_{l i m, i}}{J_{2}\left(\underline{X}_{i}\right)}\right\rangle \underline{X}_{i} \dot{p}$

where $\boldsymbol{X}_{\text {lim }, \boldsymbol{i}}$ is the threshold value, $\frac{2}{3} *\left(\boldsymbol{C}_{\boldsymbol{i}} / \gamma_{\boldsymbol{i}}+\boldsymbol{X}_{\text {lim }, \boldsymbol{i}}\right)$ is the saturation value in the uniaxial case and $\gamma_{i}$ rules the kinetic of the kinematic hardening. When plasticity initiates, $\boldsymbol{J}_{\mathbf{2}}\left(\boldsymbol{X}_{\boldsymbol{i}}\right)<\boldsymbol{X}_{\text {lim }, \boldsymbol{i}}$, the hardening is linear, as in the Prager model [40]. When the hardening reaches the threshold value $\boldsymbol{X}_{\text {lim, }, \boldsymbol{i}}$, it describes a non-linear kinematic hardening as in the Armstrong-Frederick model [27].

The isotropic hardening is adapted from the Voce model [28] to obtain a similar behavior

$\dot{\boldsymbol{R}}_{\boldsymbol{i}}=\boldsymbol{b}_{\boldsymbol{i}}\left(\boldsymbol{Q}_{\boldsymbol{i}}-\left\langle\left|\boldsymbol{R}_{\boldsymbol{i}}\right|-\boldsymbol{R}_{\text {lim }, i}\right\rangle\right) \dot{\boldsymbol{p}}$

where $\boldsymbol{R}_{\text {lim }, i}$ is the threshold value, $\boldsymbol{Q}_{\boldsymbol{i}}+\boldsymbol{R}_{\text {lim }, \boldsymbol{i}}$ is the saturation value and $\boldsymbol{b}_{\boldsymbol{i}}$ rules the kinetic of the isotropic hardening.
The equivalent cumulative plasticity rate is defined as

$\mathrm{dp}=\sqrt{\frac{2}{3} \mathrm{~d} \epsilon_{-}: \mathrm{d} \epsilon_{-}}$.

The plasticity flow is calculated using the normality rule given by

$\mathrm{d} \epsilon_{p}=\mathrm{d} p \frac{3}{2} \frac{\left(\underline{\sigma}^{D}-\underline{X}\right)}{J_{2}\left(\underline{\sigma}-\sum \underline{X_{i}}\right)}$

with $\underline{\sigma}^{D}$ the deviatoric stress tensor.

To identify the hardening parameters, the threshold hardening values $\boldsymbol{R}_{\text {lim, } i}$ and $\boldsymbol{X}_{\text {lim }, \boldsymbol{i}}$ are set at zero initially. The model identified is thus a mixed model using the Voce isotropic hardening model and the Armstrong-Frederick kinematic hardening model. This behavior law is called "Law 1". Besides an easier description of the identification procedure, the introduction of this first law will later help to point out the advantages of the second behavior law that uses threshold hardenings ("Law 2") to improve the description of the cyclic behavior.

A sequential identification in which each parameter is identified separately is proposed here. The complete identification of the first behavior law is described in the following:

(1) First, the yield strength $\sigma_{\boldsymbol{y}}$ and the elastic modulus $\boldsymbol{E}$ are determined.

(2) The tensile behavior is identified using as many kinematic hardenings as necessary. Here, one non-linear kinematic hardening $\underline{X}_{1}$ (parameters $\boldsymbol{C}_{\mathbf{1}}$ and $\gamma_{1}$ ) and one linear kinematic hardening $\boldsymbol{X}_{2}$ (parameters $\boldsymbol{C}_{2}$ and $\gamma_{2}=\mathbf{0}$ ) are used.

(3) Then, isotropic hardening is identified with as many isotropic hardenings as necessary. In this study, only one isotropic hardening $\boldsymbol{R}_{\mathbf{1}}$ was used, using parameters $\boldsymbol{b}_{\mathbf{1}}$ and $\boldsymbol{Q}_{\mathbf{1}}$. However, the description of the tensile curve is then modified by the introduction of isotropic hardening and needs to be corrected.

(4) To compensate this influence, a third kinematic hardening $\left(\boldsymbol{X}_{3}\right)$ is added by defining parameters as $C_{3}=-\boldsymbol{b}_{1} Q_{1}$ and $\gamma_{3}=\boldsymbol{b}_{1}$.

This procedure can be set on this material because the isotropic hardening is negative (the size of the elastic domain decreases with plastic strain), leading to a negative value of the $Q_{1}$ parameter and thus to a positive value of $\boldsymbol{C}_{3}$ parameter. Nevertheless, in the case of a positive isotropic hardening, this procedure has to be adjusted as it would lead to a negative $\boldsymbol{C}_{3}$ parameter. In that case, steps $2-4$ are applied replacing isotropic hardenings by kinematic hardenings and vice-versa.

As previously stated, a second behavior law is identified. In this law, $\boldsymbol{X}_{\text {lim }, \boldsymbol{i}}$ and $\boldsymbol{R}_{\text {lim }, i}$ values are still set at zero except for the isotropic and kinematic hardenings identified in steps 3 and 4 in the previous sequential identification procedure, $\left(\underline{X}_{3}\right.$ and $\left.\boldsymbol{R}_{1}\right)$. To conserve the hardenings mutual compensation, the non-zero threshold values are set equal, i.e., $\boldsymbol{X}_{\text {lim }, 3}=\boldsymbol{R}_{\text {lim }, \mathbf{1}}$. The threshold value is optimized to suppress any step effect in the mean stress relaxation curve, visible in Fig. 12 and described in the next section.

Identified parameters for both behavior laws are given in Tables 1 and 2. Parameters $\gamma_{2}, \boldsymbol{X}_{\text {lim, } 1}$ and $\boldsymbol{X}_{\text {lim }, 2}$ are equal to zero. $\boldsymbol{C}_{\boldsymbol{i}}, \boldsymbol{X}_{\text {lim, }, \boldsymbol{i}}, \boldsymbol{Q}_{\boldsymbol{i}}$, and $\boldsymbol{R}_{\text {lim }, i}$ are divided by the elastic limit $\sigma_{\boldsymbol{y}}$ for confidentiality matters.

Both identified laws are presented in Fig. 6 showing that the measured tensile behavior as well as the hardening evolutions can be correctly described by the two laws. Although the kinetic of the hardenings is slightly modified by the presence of an initial linear behavior in Law 2 , the monotonic tensile curve is not influenced by the thresholds parameters as the hardenings still compensate each other. The main interest induced by the presence of thresholds can be underlined by the cyclic behavior study presented in the next section.

\subsection{Material cyclic properties}

Uniaxial purely alternated strain-controlled tests $\left(\boldsymbol{R}_{\boldsymbol{\epsilon}}=-\mathbf{1}\right)$ were 
a)

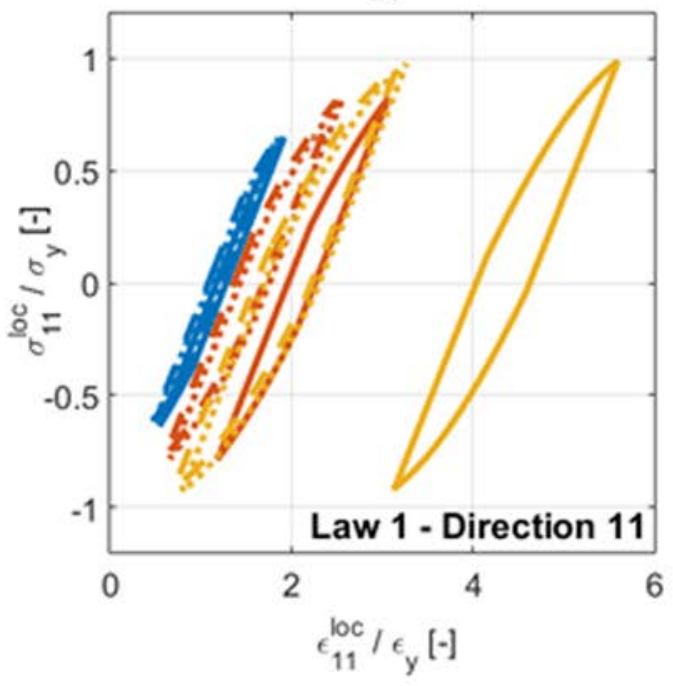

c)

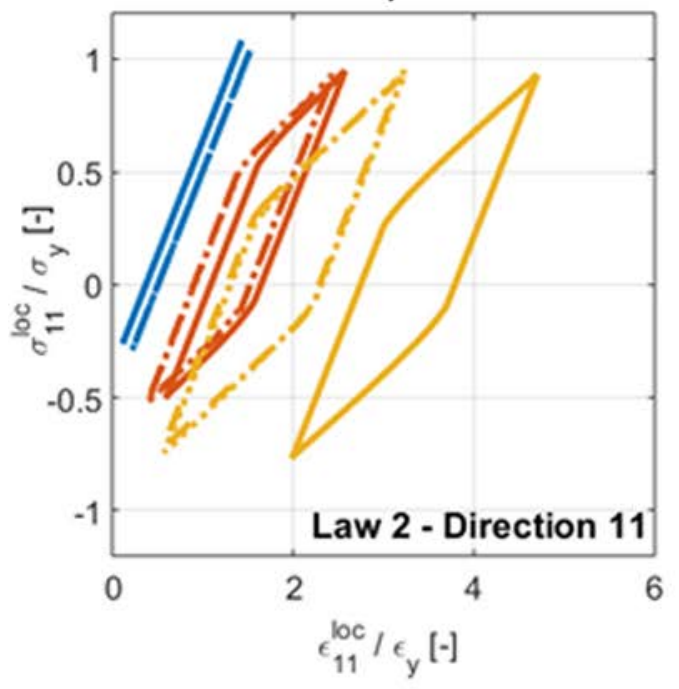

b)

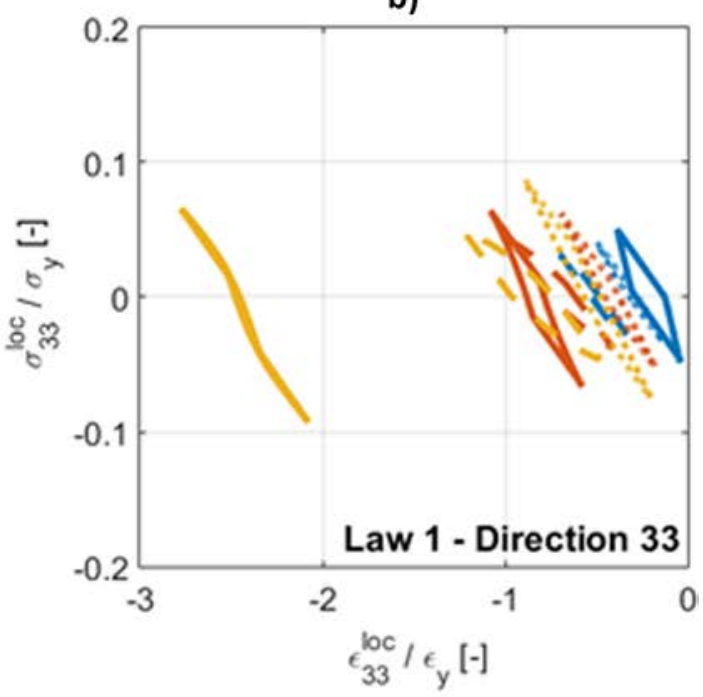

d)

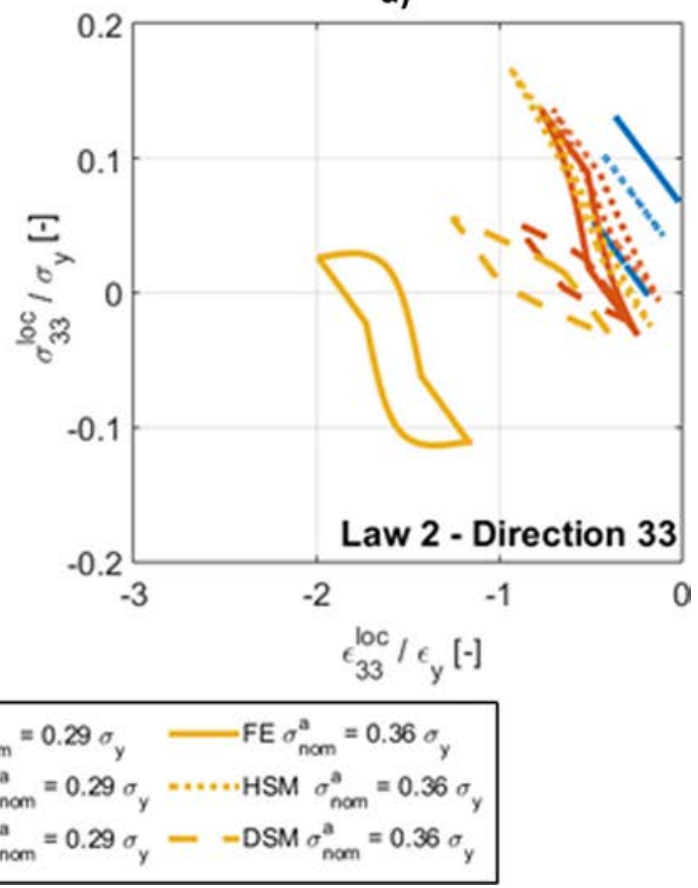

Fig. 17. Stabilized curves in direction 11 and 33 for the two behavior laws at $\boldsymbol{R}_{\sigma}^{\text {nom }}=\mathbf{0}$ for three load levels.

carried out on axisymmetric specimen to calibrate the Manson-CoffinBasquin (MCB) criterion $[41,42]$ given by

$\frac{\Delta \varepsilon}{2}=\frac{\Delta \varepsilon_{e}}{2}+\frac{\Delta \varepsilon_{p}}{2}=\frac{\sigma_{f}^{\prime}}{E_{0}}\left(2 . N_{r}\right)^{b}+\varepsilon_{f}^{\prime}\left(2 . N_{r}\right)^{c}$.

where $\Delta \boldsymbol{\epsilon} / \mathbf{2}$ is the strain amplitude, $\sigma_{f}^{\prime}$ and $\boldsymbol{b}$ (resp. $\varepsilon_{f}^{\prime}$ and $\boldsymbol{c}$ ) are parameters of the elastic (resp. plastic) regression in a log-log diagram, shown in Fig. 7 [16].

Three other load ratios were considered to study their effect on the fatigue life:

- Repeated strain-imposed tests $\left(R_{\epsilon}=\mathbf{0}\right)$,

- Alternated tests with positive mean strain $\left(R_{\epsilon}=-\mathbf{0 . 2}\right)$,

- Alternated tests with compressive mean strain $\left(R_{\epsilon}=-5\right)$.

The strain ratio influence is shown on the stabilized stress-strain curves (Fig. 8). Partial mean stress relaxation can be observed for the lowest strain amplitudes whereas a complete mean stress relaxation is observed for the highest strain amplitude levels, whatever the load ratio.

The consequence of the strain ratio on the fatigue life is shown in Fig. 9. Compressive load ratios corresponding to $R_{\varepsilon}<-\mathbf{1}$ do not affect the fatigue life whereas tensile load ratios with $R_{\varepsilon}>-\mathbf{1}$ do reduce the fatigue life. This observation can be explained if both main effects of the strain ratio are considered. The first effect is the modification of the mean stress itself, which enhances the fatigue life if mean stress is compressive or reduces it otherwise. The second effect is the increasing of the maximum absolute plastic strain, which increases the damage and thus reduces the fatigue life. In the case of a tensile load ratio, both effects decrease the fatigue life, whereas they can compensate each other, in the case of negative mean stress as illustrated in Fig. 10. Generally, the load ratio effect is taken into account introducing the mean stress $\sigma_{m}$ influence or the maximum stress $\sigma_{\max }$ influence in MCB criterion. In the first case, this corresponds to the Morrow criterion [1] 
a)

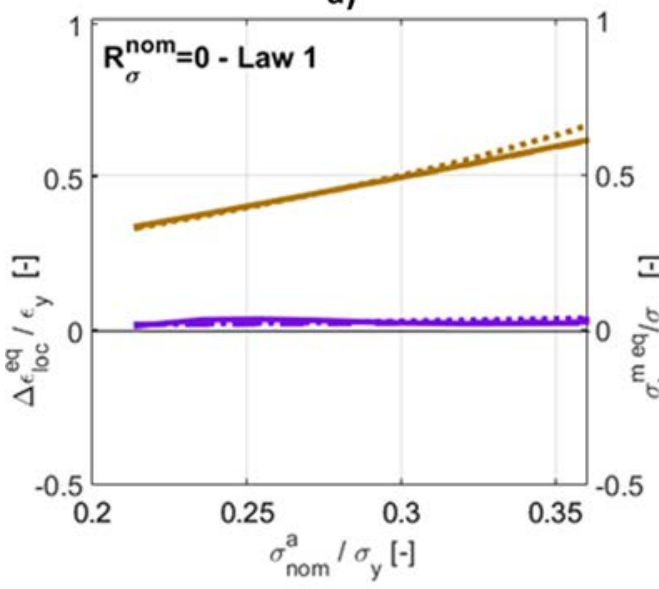

c)

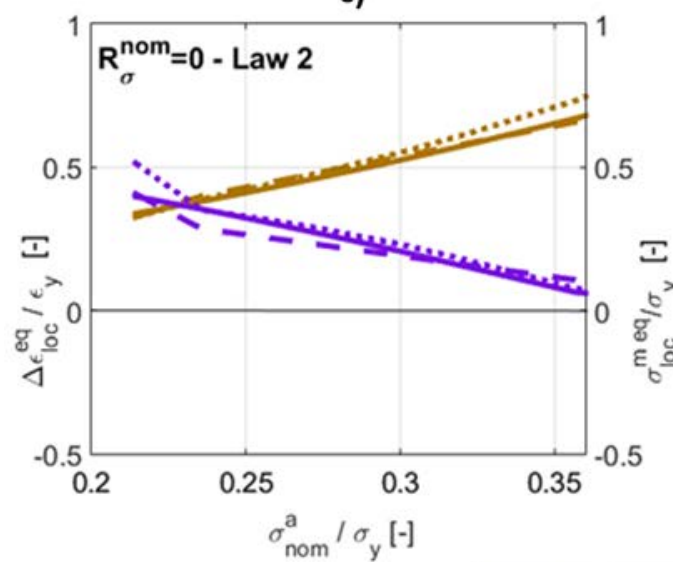

b)

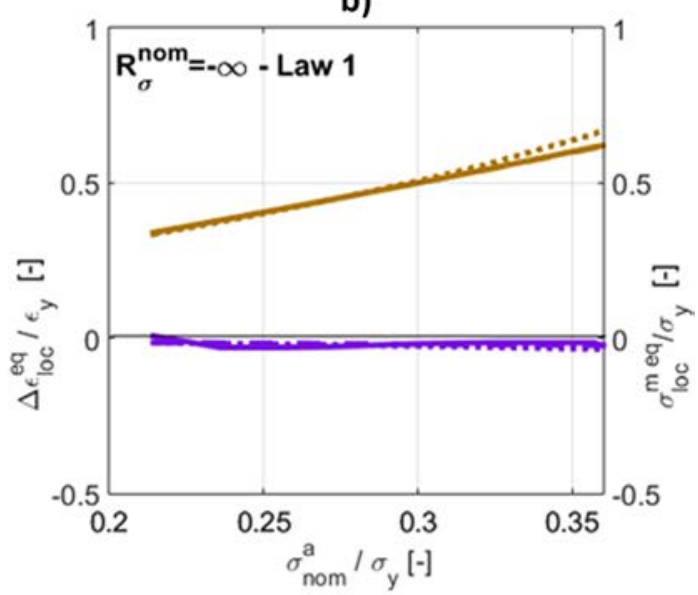

d)

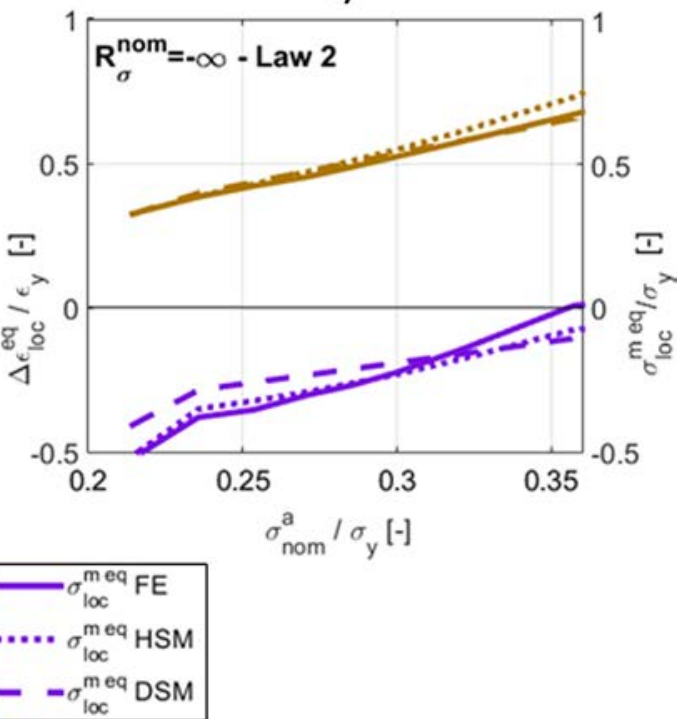

Fig. 18. Stabilized parameters for the two behavior laws and the two load ratios $\left(\boldsymbol{R}_{\sigma}^{\text {nom }}=\mathbf{0}\right.$ and $\left.\boldsymbol{R}_{\sigma}^{\text {nom }}=-\infty\right)$.

that is formulated as

$\frac{\Delta \varepsilon}{2}=\frac{\sigma_{f}^{\prime}-\sigma_{m}}{E}\left(2 \cdot N_{r}\right)^{b}+\varepsilon_{f}^{\prime}\left(2 \cdot N_{r}\right)^{c}$.

In the second case, this corresponds to the Smith-Watson-Topper (SWT) [2] criterion that is expressed as

$\frac{\Delta \varepsilon}{2}=\left[\frac{\sigma_{f}^{\prime 2}}{E}\left(2 \cdot N_{r}\right)^{2 b}+\sigma_{f}^{\prime} \varepsilon_{f}^{\prime}\left(2 \cdot N_{r}\right)^{b+c}\right] \frac{1}{\sigma_{\max }}$.

Both criteria cannot take into account the experimentally observed asymmetric effect of the load ratio (Fig. 9). A modified Morrow criterion (MM) is thus proposed considering the positive part of the mean stress, noted using Macaulay brackets $\left\langle\sigma_{m}\right\rangle$. The modified Morrow criterion is thus defined by

$\frac{\Delta \varepsilon}{2}=\frac{\sigma_{f}^{\prime}-\left\langle\sigma_{m}\right\rangle}{E}\left(2 \cdot N_{r}\right)^{b}+\varepsilon_{f}^{\prime}\left(2 \cdot N_{r}\right)^{c}$.

The comparison of experimental versus predicted fatigue lifespans for the four criteria (MCB, Morrow, SWT and MM) using the experimental stabilized values is shown in Fig. 11. Predictions are improved with the MM criterion, which is also the only one to predict conservative fatigue life whatever the load ratio.

The last validation step of the fatigue criteria consists in using the predicted stabilized stress-strain curves, instead of the experimental ones. The predicted mean stress is thus compared to the experimental mean stresses in Fig. 12. It shows that, with the behavior Law 1, a complete mean stress relaxation is predicted for strain amplitudes higher than $0.7 \epsilon_{y}$. It leads to an underestimation of the stabilized mean stress which implies non-conservative fatigue life predictions. With the behavior Law 2, a partial mean stress relaxation is obtained. Mean stress absolute values are uniformly overestimated which could be due to a long term softening of the material that is not taken into account in the model.

Fig. 13 shows the influence of the behavior law on the fatigue lifespans obtained using the modified Morrow criterion with the predicted stabilized stress-strain curves. Predictions are more conservative using Law 2 than using Law 1 that can underestimate the stabilized mean stress. The conservatism factor can be as high as three for the highest lifespan of cyclic test with positive mean strain. This corresponds to applied strain amplitudes lower than $\mathbf{0 . 7} \epsilon_{y}$ where the mean stress is slightly overestimated, whatever the chosen behavior law. For applied strain amplitudes higher than $\mathbf{0 . 7} \epsilon_{y}$ or for cyclic tests with negative mean strain, lifespans are correctly predicted. 
a)

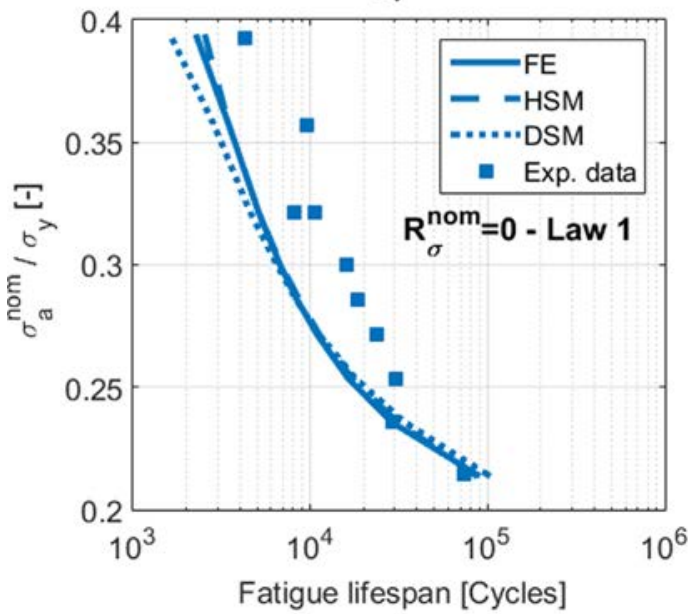

c)

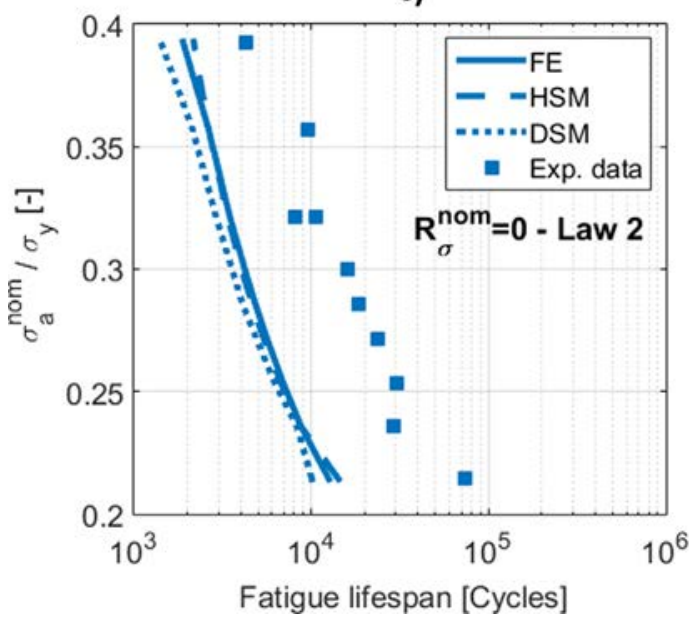

b)

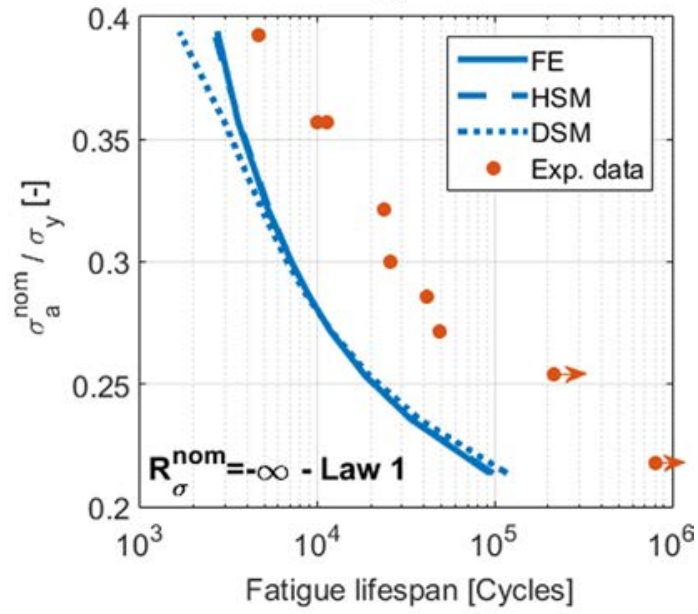

d)

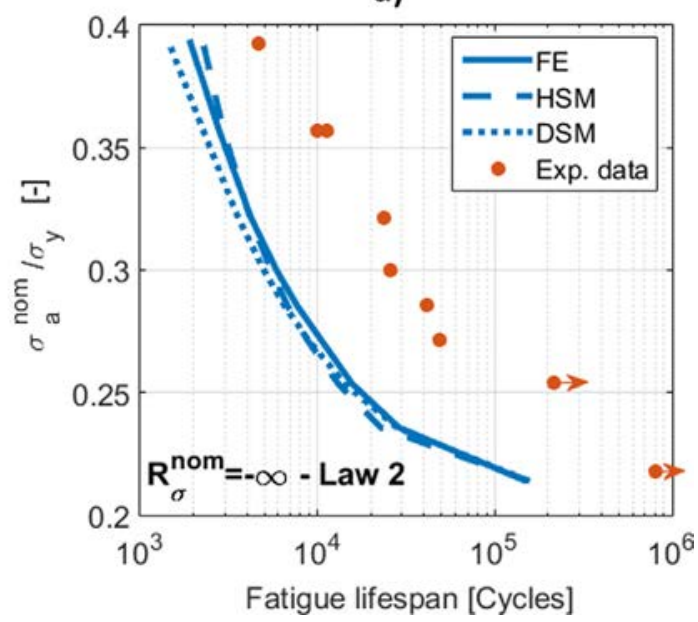

Fig. 19. Comparison of fatigue lifespans predicted using the modified Morrow criterion with FE and SM with experimental data.

a)

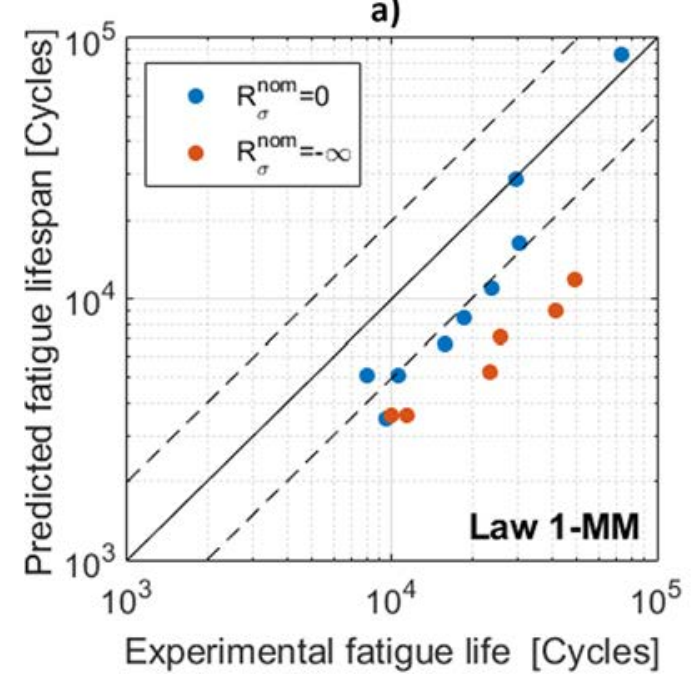

b)

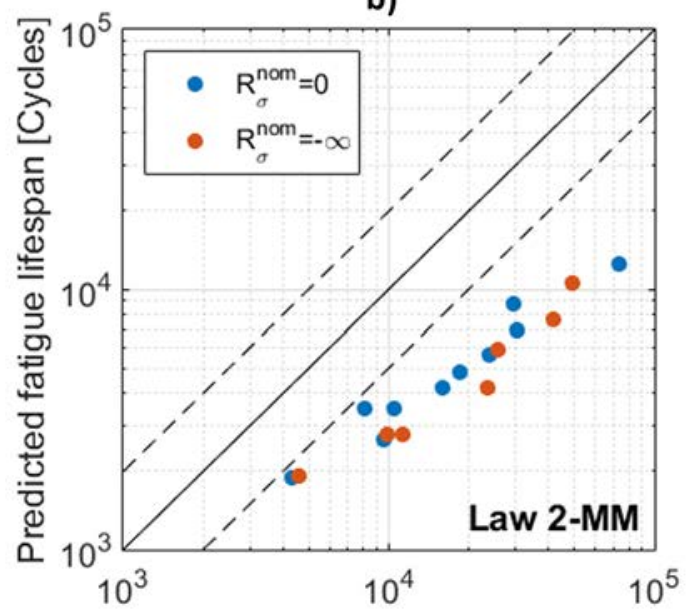

Experimental fatigue lifespan [Cycles]

Fig. 20. Fatigue life prediction using HSM and the modified Morrow criterion for the two load $\operatorname{ratios}\left(\boldsymbol{R}_{\sigma}^{\text {nom }}=\mathbf{0}\right.$ and $\left.\boldsymbol{R}_{\sigma}^{\text {nom }}=-\infty\right)$.

\section{Prediction of the stabilised local behavior}

\subsection{Finite element modeling and validation}

One fourth of the double-notched specimen was meshed using 8- node hexahedra with linear integration. The in-plane mesh was extruded to obtain the 3D model as shown in Fig. 14 (10 elements are used through the thickness). Experimental gauge measurements at the notch tip were accomplished using KYOWA ${ }^{\circledR}$ KFG-02-120-C1-11 strain gauges. Correlation between strain range measurements and $\mathrm{FE}$ 


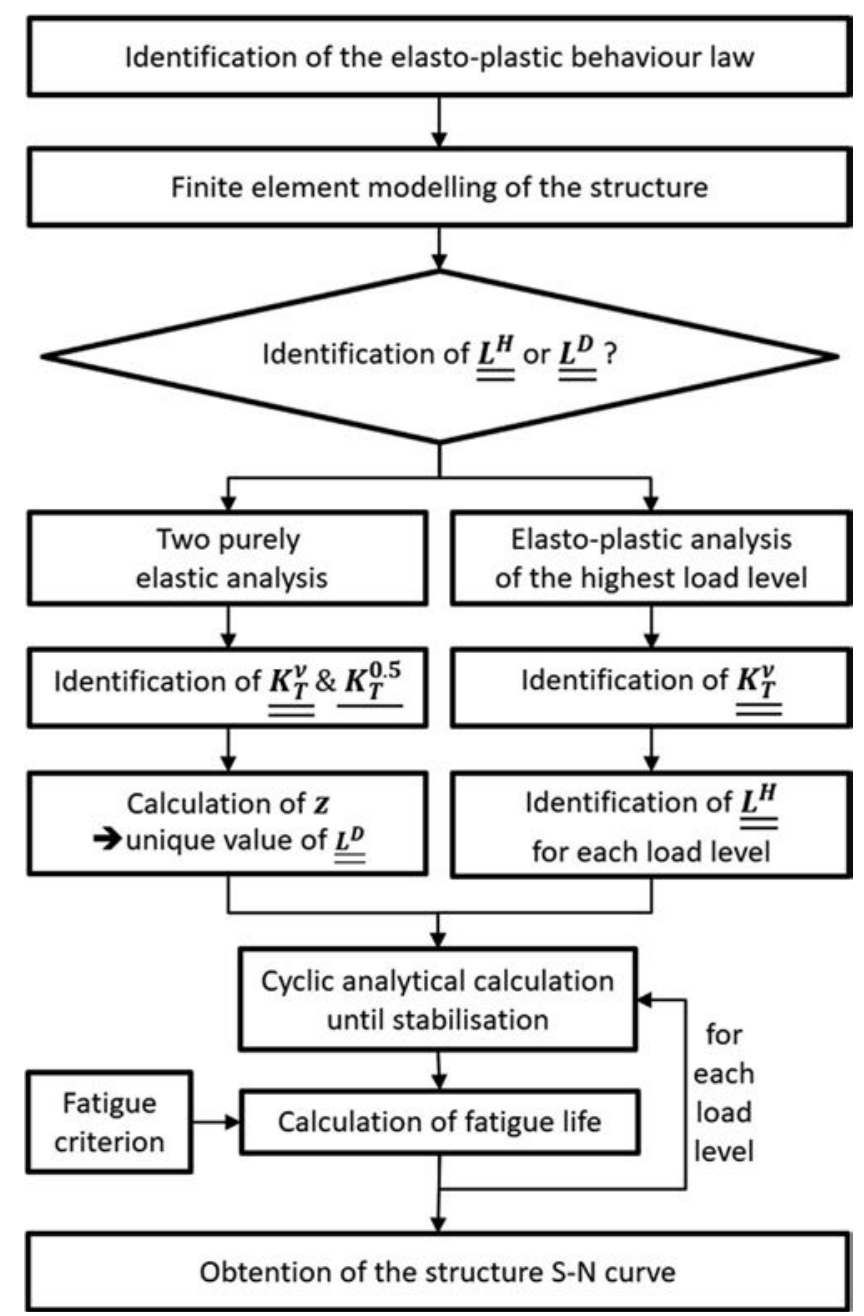

Fig. 21. Full fatigue life design chain diagram.

predictions is shown in Fig. 15. It shows that both behavior laws can predict the strain amplitude but only Law 2 can predict an influence of the nominal load ratio on the local maximum principal stress ratio defined as

$\boldsymbol{R}_{\sigma}^{l o c}=\frac{\sigma_{\min }^{l o c}}{\sigma_{\max }^{l o c}}$.

Fig. 16 shows that, whatever the nominal load ratio and level, the predicted local stress ratio with behavior Law 1 is close to -1 , indicating that the mean stress is totally relaxed. It implies thus that, according to Law 1, the nominal load ratio has no effect on the local load ratio and thus on the fatigue life, which is in contradiction with the obtained experimental results (Fig. 2). On the contrary, using behavior Law 2 , the predicted local stress ratio varies from -5 to -1 for repeated compressive nominal loadings and from -0.2 to -1 for repeated tensile nominal loadings.

\subsection{Simplified methods validation}

Cyclic behavior can then be obtained for both localization operators. Stabilized curves at $R_{\sigma}^{\text {nom }}=\mathbf{0}$, obtained using both simplified methods (HSM and DSM) are plotted in Fig. 17 and compared to FE. Curves are plotted for three load levels: the highest and lowest bounds used for the fatigue testing $\left(\sigma_{a}^{\text {nom }}=\mathbf{0 . 2 1} \sigma_{y}\right.$ and $\left.\sigma_{a}^{\text {nom }}=\mathbf{0 . 3 6} \sigma_{y}\right)$ and a medium level $\left(\sigma_{a}^{\text {nom }}=\mathbf{0 . 2 9} \sigma_{y}\right)$.

The shape of the stabilized curves obtained using simplified methods is similar to those obtained with FE, especially in the principal direction. For both load ratios and behavior laws, the shape and the size of the stabilized curves are correctly described although the maximum and minimum strain are underestimated by simplified methods, in comparison with FE curves. Fortunately, the only strain parameter used in the fatigue criteria is the strain amplitude which is similar between the different methods.

\section{Fatigue life prediction using stabilized stress-strain curves}

\subsection{Multiaxial formulation of fatigue parameters}

In order to obtain fatigue lifespan for the notched specimens using the modified Morrow (MM) criterion, a multiaxial formulation using equivalent scalar parameters has to be employed as expressed in the following relationship

$\frac{\Delta \epsilon_{e q}}{2}=\frac{\sigma_{f}^{\prime}-\left\langle\sigma_{m}^{e q}\right\rangle}{E}\left(2 \cdot N_{r}\right)^{b}+\varepsilon_{f}^{\prime}\left(2 \cdot N_{r}\right)^{c}$.

Some formulations have been proposed based on von Mises formulations of the strain amplitude and maximum stress [44]. Here, an equivalent strain amplitude parameter is used, written as

$\Delta \epsilon_{e q}=\sqrt{\frac{\Delta \epsilon^{e}: \Delta \epsilon^{e}}{1+2 \nu^{2}}}+\sqrt{\frac{2}{3} \Delta \epsilon^{p}: \Delta \epsilon^{p}}$.

It can be linked to a critical plane approach under an uniaxial strain but unlike such approaches, it can be easily implemented in a finite element code, as it is not necessary to determine a critical plane.

In order to preserve the mean stress sign, the von Mises equivalent stress cannot be employed directly as it would lead to positive equivalent mean stress under compressive loadings. For this reason, the first invariant of the mean stress is chosen to apply the MM criterion

$\sigma_{m}^{e q}=\operatorname{tr}\left(\underline{\sigma}_{m}\right)$

A comparison of the stabilized values of both equivalent parameters used in the proposed fatigue criterion is shown in Fig. 18. It appears that, whatever the behavior law, parameters obtained using simplified methods are very similar to FE. It is important to note that the equivalent mean stress is always totally relaxed with Law 1 whatever the load ratio or level, whereas Law 2 predicts an effect of the load ratio and load level.

The highest difference in the predicted equivalent mean stress, between simplified method results and FE results, reaches $0.18 \sigma_{y}$. It comes from the difference in the mean stress prediction in the $\vec{e}_{3}$ direction as indicated by the stabilized curves in Fig. 10d). However, this variance does not induce a significative change in fatigue life prediction as will be shown later. The equivalent strain amplitude is less sensitive to this difference because of the quadratic norm employed in Eq. (27).

\subsection{Fatigue life prediction}

The fatigue life predictions obtained using the MM criterion are plotted in Fig. 19. The first observation is that all criteria and methods are conservative. Predictions obtained with both simplified methods are very similar to those obtained using finite elements, showing that the differences observed on the stress-strain curves and on the stabilized equivalent parameters are negligible, with respect to the global conservatism of the whole design process. This conclusion is in accord with [45].

To complete and conclude this study, Fig. 20 shows the comparison between the experimental data and the predicted fatigue lifespans with the MM fatigue criterion and Herbland simplified method. The factor of security appears to be dependent of the load ratio with Law 1 but not with Law 2. A slight dependence on the load level can be observed with Law 2, which may be explained by a potential long-term softening of the material that cannot be taken into account by the behavior law. 
The global conservatism is not linked to the proposed simplified approach as results obtained with finite element analysis are identical. The first order factor in the fatigue life criterion is the strain amplitude which suggests that the prediction obtained with both methods overestimate the real strain amplitude. However, the strain amplitude values predicted with the behavior law (whether it is with the simplified method or with finite element analysis) are very close to the strain gauges measurements shown in Fig. 15. The main hypothesis of the important conservatism factor is, in the author's opinion, the strain amplitude gradient around the notch. Indeed, the volume that undergoes the maximum strain amplitude differs in the case of the criterion calibration specimens and the notched specimen. To take this effect into account, an effective volume approach could be used [46].

\section{Conclusion}

In this study, a full design chain to predict fatigue life of structures in confined plasticity cases was presented. This method is sum-up in Fig. 21. The main conclusions on the different steps of the proposed design chain are:

- The mean stress cannot be predicted correctly with classic nonlinear hardenings as proposed by Armstrong \& Frederick or Voce. Threshold kinematic hardenings, as proposed by Chaboche, can be used to enhance the mean stress prediction. In this paper, a similar non-linear isotropic hardening with threshold is proposed to permit a sequential identification of the behavior law using a particular load-unload test.

- Simplified methods based on the use of an adjustable scale transition rule can be used to predict the stabilized cyclic stress-strain curve. Darlet's and Herbland's localization operators were compared in this study and have shown similar capability. Fatigue life predictions obtained using both approaches are also similar to those obtained using FE showing that the use of the simplified method only reduces the computation time but not the fatigue life prediction accuracy.

- As Darlet's operator only requires elastic calculations, it is easier to implement than Herbland's approach, especially if the behavior law is not already implemented in the finite element code. However, validation of the approach on multiaxial and non-proportional loads could also help to choose one or the other approach. Comparison between these two approaches and other already existing methods will be of interest for future work.

- The method could be enhanced to reduce the conservatism. The material volume that undergo the same load is different between the calibration samples and the notched specimen. This could explain part of the conservatism because of the local approach. The use of an effective volume approach could help to reduce the conservatism factor [46]. The over-estimation of the mean stress could also be a reason of the conservatism.

- The particular case of compressive loads was studied. Tensile mean stress reduces the fatigue life whereas compressive mean stress does not affect it. A modified version of the Morrow criterion is proposed to account for this effect.

\section{Declaration of Competing Interest}

The authors declare that they have no known competing financial interests or personal relationships that could have appeared to influence the work reported in this paper.

\section{Acknowledgements}

The financial support of DGA/MRIS (Mission for Scientific Research and Innovation) is gratefully acknowledged.

\section{Bibliography}

[1] J. Morrow, Low cycle fatigue behavior of quenched and tempered SAE 1045 steel, 1965.

[2] K. Smith, P. Watson, T. Topper, A stress-strain function for the fatigue of metals, J. Mater. 4 (1970) 767-778.

[3] H. Neuber, Theory of stress concentration for shear-strained prismatical bodies with arbitrary nonlinear stress-strain law, J. Appl. Mech. 28 (4) (1961) 544-550.

[4] K. Molski, G. Glinka, A method of elastic-plastic stress and strain calculation at a notch root, Mater. Sci. Eng. 50 (1) (1981) 93-100.

[5] A. Moftakhar, A. Buczynski, G. Glinka, Calculation of elasto-plastic strains and stresses in notches under multiaxial loading, Int. J. Fract. 70 (4) (1995) 357-373.

[6] D. Kujawski, On energy interpretations of the Neuber's rule, Theor. Appl. Fract. Mech. 73 (2014) 91-96.

[7] D. Kujawski, P.C. Sree, On deviatoric interpretation of Neuber's rule and the SWT parameter, Theor. Appl. Fract. Mech. 71 (2014) 44-50.

[8] D. Ye, S. Matsuoka, N. Suzuki, Y. Maeda, Further investigation of Neuber's rule and the equivalent strain energy density (ESED) method, Int. J. Fatigue 26 (5) (2004) $447-455$.

[9] R. Desmorat, Fast estimation of localized plasticity and damage by energetic methods, Int. J. Solids Struct. 39 (12) (2002) 3289-3310.

[10] M. Zappalorto, D. Kujawski, Neuber's rules and other solutions: Theoretical differences, formal analogies and energy interpretations, Theor. Appl. Fract. Mech. 79 (2015) 2-13.

[11] M. Hoffmann, T. Seeger, Generalized method for estimating multiaxial elasticplastic notch stresses and strains. Part 1: Theory, J. Eng. Mater. Technol. Trans. ASME 107 (4) (1985) 250-260.

[12] M.E. Barkey, D.F. Socie, K.J. Hsia, Yield surface approach to the estimation of notch strains for proportional and nonproportional cyclic loading, J. Eng. Mater. Technol. Trans. ASME 116 (2) (1994) 173-180.

[13] R. Sethuraman, S.V. Gupta, Evaluation of notch root elasto-plastic stress-strain state for general loadings using an elastic solution, Int. J. Press. Vessels Pip. 81 (4) (2004) $313-325$.

[14] D. Ye, O. Hertel, M. Vormwald, A unified expression of elastic-plastic notch stress-strain calculation in bodies subjected to multiaxial cyclic loading, Int. J. Solids Struct. 45 (24) (2008) 6177-6189.

[15] A. Darlet, R. Desmorat, Stress triaxiality and Lode angle along surfaces of elastoplastic structures, Int. J. Solids Struct. 67-68 (2015) 71-83.

[16] A. Buczynski, G. Glinka, An analysis of elasto-plastic strains and stresses in notched bodies subjected to cyclic non-proportional loading paths, Eur. Struct. Integr. Soc. 31 (2003) 265-283.

[17] S. Kilambi, S.M. Tipton, Algorithm to estimate notch root strain in tension using numerical analysis, Theor. Appl. Fract. Mech. 77 (2015) 1-13.

[18] J.-Y. Lim, S.-G. Hong, S.-B. Lee, Application of local stress-strain approaches in the prediction of fatigue crack initiation life for cyclically non-stabilized and nonMasing steel, Int. J. Fatigue 27 (10) (2005) 1653-1660.

[19] Z. Salemi, D. Kujawski, A strain energy method for elastic-plastic analysis of notches under shear loading, Theor. Appl. Fract. Mech. 84 (2016) 49-56.

[20] S. Kilambi, S.M. Tipton, Numerical evaluation of the original 'Neuber's rule' for pure out-of-plane shear loading, J. Strain Anal. Eng. Des. 48 (8) (2013) 522-535.

[21] T. Herbland, G. Cailletaud, S. Quilici, H. Jaffal, A new technique for the fatigue life prediction in notched compoenents, Cetim Senlis.

[22] T. Hanaki, Y. Hayashi, H. Akebono, M. Kato, A. Sugeta, Effect of compression residual stress on fatigue properties of stainless cast steel, Procedia Struct. Integr. 2 (2016) 3143-3149.

[23] M. Kamaya, M. Kawakubo, Mean stress effect on fatigue strength of stainless steel, Int. J. Fatigue 74 (2015) 20-29.

[24] A. Ince, G. Glinka, A modification of Morrow and Smith-Watson-Topper mean stress correction models, Fatigue Fract. Eng. Mater. Struct. 34 (11) (2011) 854-867.

[25] S.K. Paul, N. Stanford, A. Taylor, T. Hilditch, The effect of low cycle fatigue, ratcheting and mean stress relaxation on stress-strain response and microstructural development in a dual phase steel, Int. J. Fatigue 80 (2015) 341-348.

[26] D. Kujawski, F. Ellyin, A unified approach to mean stress effect on fatigue threshold conditions, Int. J. Fatigue 17 (2) (1995) 101-106.

[27] P.J. Armstrong, C.O. Frederick, A mathematical representation of the multiaxial Bauschinger effect. Central Electricity Generating Board [and] Berkeley Nuclear Laboratories, Research \& Development Department, 1966.

[28] E. Voce, A practical strain-hardening function, Metallurgica 51 (1955) 219-226.

[29] J.L. Chaboche, On some modifications of kinematic hardening to improve the description of ratchetting effects, Int. J. Plast. 7 (7) (1991) 661-678.

[30] Matelect, Practical aspects of the ACPD technique, User Manual.

[31] F. Ellyin, D. Kujawski, An energy-based fatigue failure criterion, Microstruct. Mech. Behav. Mater. 2 (1985) 591-600.

[32] T. Herbland, Une méthode de correction élastoplastique pour le calcul en fatigue des zones de concentration de contraintes sous chargement cyclique multiaxial non proportionnel, Thèse, Mines ParisTech, Paris, 2009.

[33] M. Chouman, A. Gaubert, J.L. Chaboche, P. Kanoute, G. Cailletaud, S. Quilici, Elastic-viscoplastic notch correction methods, Int. J. Solids Struct. 51 (18) (2014) 3025-3041.

[34] J.D. Eshelby, The determination of the elastic field of an ellipsoidal inclusion, and related problems, Proc. Roy. Soc. Lond. Math. Phys. Eng. Sci. 241 (1226) (1957) 376-396.

[35] E. Kröner, Zur plastischen verformung des vielkristalls, Acta Metall. 9 (2) (1961) 155-161.

[36] M. Berveiller, A. Zaoui, An extension of the self-consistent scheme to plastically- 
flowing polycrystals, J. Mech. Phys. Solids 26 (1979) 325-344.

[37] M. Sauzay, Effets de surface et d'anisotropie en fatigue multiaxiale, Thèse de doctorat, Paris 6 (2000).

[38] J. Lemaitre, J.-L. Chaboche, Mechanics of Solid Materials, Cambridge University Press, 1994.

[39] J.L. Chaboche, Constitutive equations for cyclic plasticity and cyclic viscoplasticity, Int. J. Plast. 5 (3) (1989) 247-302.

[40] W. Prager, Recent developments in the mathematical theory of plasticity, J. Appl. Phys. 20 (3) (1949) 235-241.

[41] S.S. Manson, Fatigue: A complex subject-Some simple approximations, Exp. Mech. 5 (4) (1965) 193-226.
[42] L.F. Coffin, A study of the effect of cyclic thermal stresses on a ductile metal, vol. 76, 1954, pp. 931-950.

[44] X. Chen, J. Song, K.S. Kim, Low cycle fatigue life prediction of 63Sn-37Pb solder under proportional and non-proportional loading, Int. J. Fatigue 28 (7) (2006) $757-766$.

[45] S.K. Visvanatha, P.V. Straznicky, R.L. Hewitt, Influence of strain estimation methods on life predictions using the local strain approach, Int. J. Fatigue 22 (8) (2000) 675-681.

[46] G. Härkegård, H. Halleraker, Assessment of methods for prediction of notch and size effects at the fatigue limit based on test data by Böhm and Magin, Int. J. Fatigue 32 (10) (2010) 1701-1709. 